\title{
NUOVI ELEMENTI DI STORIA URBANA NEL REGNO DI SARDEGNA: \\ DALLA FONDAZIONE DI BONARIA \\ AL POPOLAMENTO CATALANO DI CASTEL DI CAGLIARI
}

\author{
MARIA BONARIA URBAN \\ Università di Cagliari
}

\section{SOMMARIO}

1. La conquista catalana.- 2. Lo sviluppo urbano di Bonaria.- 3. Da Bonaria a Castel di Cagliari.- 4. Il progetto di insediamento nella Lapola.5. Castel di Cagliari caput totius regni Sardiniae.

\section{LA CONQUISTA CATALANA}

Nonostante il notevole benessere economico raggiunto, la supremazia pisana a Castel di Cagliari non fu di lunga durata' ${ }^{1}$. L'investitura papale a

\footnotetext{
'La bibliografia sulla presenza pisana in Sardegna è molto ampia, mi limito a segnalare, oltre agli ormai classici studi di E. BESTA, La Sardegna medioevale, 2 voll., Palermo, 1908-09 e A. SolmI, Studi storici sulle istituzioni della Sardegna nel Medioevo, Cagliari, 1917, alcuni titoli più recenti: A. Boscolo, Sardegna, Pisa, Genova nel Medioevo, Genova, 1978; ID., L'abbazia di San Vittore, Pisa e la Sardegna, Padova, 1985; F. ARTizzu, L'opera di Santa Maria di Pisa e la Sardegna, Padova, 1974; ID., La Sardegna pisana e genovese, Sassari, 1985; M. TAngheroni, Medioevo Tirrenico, Pisa, 1992; G. Meloni, La Sardegna nel quadro della politica mediterranea di Pisa, Genova, Aragona, in Storia dei Sardi e della Sardegna, II, Il Medioevo. Dai Giudicati agli Aragonesi. Milano, 1987, pp. 49-96; M. TANGHERONI, L'economia e la società della Sardegna (XI-XIII sec.), ibidem, pp. 157-191; J. HEERS, Pisani e Genovesi nella Sardegna medioevale: vita politica e sociale, ibidem, pp. 231-250; J. DAY, La Sardegna e i suoi dominatori dal secolo XI al secolo XIV, in Storia d'Italia, X, La Sardegna medioevale e moderna, Torino, 1984, pp. 3-187; S. PETRUCCI, Re in Sardegna a Pisa cittadini, Bologna, 1988; ID., Tra S. Igia e Castel di Castro di Cagliari: politica, società, insediamenti pisani nella metà del XIII secolo, in S. Igia capitale giudicale, Pisa, 1986, pp. 235-241; ID.,
} 
favore di Giacomo II pose infatti le premesse della spedizione catalana che si concluse con la conquista del regno di Sardegna e Corsica (1323-1324) ${ }^{2}$.

Lo stanziamento dei nuovi venuti nel castrum pisano non fu immediato, al contrario risultò essere il momento conclusivo di un forte scontro politico-sociale fra la corte, gli ufficiali regi presenti in Sardegna, il consiglio di Castel di Cagliari e quello di Bonaria. Protagonista degli eventi fu Alfonso, figlio ed erede di Giacomo II al trono d'Aragona, che diresse personalmente l'impresa ed ebbe un ruolo di primo piano nelle scelte politiche e urbanistiche compiute in quegli anni, contribuendo in modo decisivo allo stanziamento e alla fortificazione della villa di Bonaria, così come al definitivo trasferimento a Castel di Cagliari; al suo fianco e con ampi poteri decisionali operò, in particolare, Bernat de Boixadors, nominato governatore generale del regno di Sardegna nel corso del 1326, che ebbe anche il compito di attuare il processo di popolamento.

Numerose sono le ricerche compiute sugli aspetti politici ed economici della conquista, ma fino ad oggi non esistono studi specifici su come maturò la scelta della capitale del regno sardo. In realtà la documentazione rinvenuta permette di seguire con sufficiente precisione l'evoluzione del progetto catalano e i contrasti sorti fra i protagonisti della vicenda; la soluzione di questo problema costituiva la base su cui impostare il futuro stesso del potere aragonese, soprattutto quando, dinanzi al rischio di una ripresa della guerra, si rivelò indispensabile il disporre di un'efficace struttura difensiva in cui concentrare la resistenza. Castel di Cagliari

Forestieri a Castello di Castro in periodo pisano, in Commercio, finanza, funzione pubblica, stranieri in Sicilia e in Sardegna nei secoli XIII-XV, Napoli, 1989, pp. 219-259.

D'ora in avanti, per maggiore comodità, si utilizzeranno le seguenti sigle: ACA (Arxiu de la Corona d'Aragó); ACC (Archivio Comunale di Cagliari); AAR (Antico Archivio Regio); ANTCa (Atti dei Notai della Tappa di Cagliari); ANS (Atti dei Notai Sciolti); ASC (Archivio di Stato di Cagliari); C (Cancelleria); CR (Cartes Reials); MR (Mestre Racional); RP (Reial Patrimoni).

${ }^{2} \mathrm{~V}$. SAlaVert y ROCa, Cerdeña y la expansión mediterranea de la Corona de Aragón (1293-1314), 2 voll., Madrid, 1956; A. ARRIBAS PALAU, La conquista de Cerdeña por Jaime II de Aragón, Barcelona, 1952. F.C. CASUlA, La Sardegna catalano-aragonese, Sassari, 1990, pp. 103-ss. e pp. 329-ss. Il racconto della conquista del regno di Sardegna ci è stato tramandato anche da Pietro IV d'Aragona nella sua famosa cronaca: G. MELONI, L'Italia medioevale nella cronaca di Pietro IV d'Aragona, Cagliari, 1980, pp. 34-ss. Una ricostruzione degli eventi con molti elementi inediti in M.E. CADEDDU, Giacomo II d'Aragona e la conquista del regno di Sardegna e Corsica, in "Medioevo. Saggi e Rassegne" (d'ora in avanti "MSR"), 20 (1996), pp. 249-314. Un'analisi del sistema di finanziamento della conquista in M. SÁNCHEZ MARTÍNEZ, Contributi finanziari di città e ville della Catalogna alla conquista della Sardegna aragonese (1321-1326), ibidem, pp. 315-350. 
comunque, in virtù della sua vocazione portuale, rivendicava innanzi tutto un ruolo da protagonista nel sistema economico sardo e si proponeva come punto di convergenza tra gli interessi del mondo catalano e il mercato interno. Nonostante ciò, la scelta dell'antica città pisana quale capitale del regno sardo costituì, come abbiamo già accennato, il punto di arrivo di una complessa trattativa diplomatica che si accese fra le forze politiche e sociali all'indomani del primo accordo stipulato con il Comune di Pisa e si risolse soltanto quando Castel di Cagliari, finalmente conquistata dalle truppe aragonesi, fu ripopolata con elementi iberici ${ }^{3}$.

Tralasciando i complessi aspetti organizzativi della guerra, ci limitiamo a ricordare che, una volta conquistata la città di Iglesias ${ }^{4}$, i Catalani si trovavano in difficoltà a spezzare la resistenza dei Pisani rinchiusi a Castel di Cagliari ${ }^{5}$. Ciò contribuiva a rendere più stabile la loro presenza sul colle di Bonaria, luogo scelto per gli accampamenti che incominciava ad assumere l'aspetto di un nucleo abitato e si iniziò a fortificarlo ${ }^{6}$.

L'occasione opportuna per sconfiggere i Pisani avvenne il 29 febbraio del 1324 quando gli eserciti si scontrarono in una grande battaglia campale presso una località non lontana da Castel di Cagliari, chiamata Lutocisterna. Le truppe catalane superarono il confronto, così come la flotta, schierata nelle acque del golfo cagliaritano, combatté vittoriosamente contro i legni nemici ${ }^{7}$. Nonostante la gravità di queste sconfitte, i Pisani continua-

\footnotetext{
${ }^{3}$ Alcune fonti molto importanti sul popolamento catalano di Castel di Cagliari sono state studiate da R. CONDE y Delgado De Molina, Castell de Càller. Cagliari catalano aragonese, Cagliari, 1984.

${ }^{4}$ Sul centro minerario C. BAUdi Di Vesme, Codex Diplomaticus Ecclesiensis, Torino, 1877. Esemplare la monografia di M. TANGHERONI, La città dell'argento. Iglesias dalle origini alla fine del Medioevo, Napoli, 1985.

${ }^{5}$ F.C. Casula, La Sardegna, cit., I, p. 149. Sull'assedio di Cagliari si vedano le testimonianze studiate da M.E. CADEDDU, Giacomo II d'Aragona, cit., p. 279, nota 95; Cfr. anche M. SCARLATA, Carte reali diplomatiche di Giacomo II d'Aragona riguardanti l'Italia (1291-1327), Palermo, 1993, pp. 368-372.

${ }^{6} \mathrm{Le}$ fonti catalane ricordano che fu Alfonso a dare al colle il nome di Bonayre, cfr. R. MUNTANER, Crònica, cap. CLXXIV; ZurITA, Anales de la Corona de Aragón, 1. II, VI, c. 61. G. Meloni, L'Italia Medioevale, cit., p. 55; A. Arribas Palau, La conquista, cit., pp. 340ss.; G. TODDE, Castel de Bonayre: il primo insediamento catalano-aragonese in Sardegna, in La società mediterranea all'epoca del Vespro, XI Congresso di Storia della Corona d'Aragona (d'ora in avanti CSCA) (Palermo-Trapani-Erice 1982), IV, Palermo, 1984, p. 336.

${ }^{7}$ M.E CADEdDu, Giacomo II d'Aragona, cit., pp. 279-ss; G. Meloni, L'Italia medioevale, cit., pp. 47-55. Sulla battaglia di Lutocisterna: F.C. CASULA, La Sardegna, cit., pp. 163 e 338: il luogo della battaglia è stato individuato nell'area compresa tra le rovine di Santa Gilla e l'attuale aeroporto di Cagliari-Elmas. Deriva il suo nome dal paesaggio fangoso (in sardo luto)
} 
vano a resistere all'assedio, infatti la città riusciva a procurarsi le vettovaglie necessarie attraverso un collegamento con l'entroterra. Questa possibilità di vettovagliamento venne però bloccata da Alfonso con lo stazionamento di un centinaio di cavalieri presso la villa di Palma. Comunque i Pisani non si diedero per vinti e trovarono una nuova soluzione: costruirono un ponte coperto con le frasche nel canale che collegava lo stagno di Santa Gilla con il mare; in tal modo riuscivano ad assicurarsi i rifornimenti nella curatoria di Nures percorrendo appena dieci chilometri, mentre i Catalani, ignari di ciò, dovevano aggirare la laguna con un sentiero lungo più del triplo. Però anche quest'ultima via di salvezza, una volta scoperta, venne neutralizzata, in quanto Alfonso fece costruire nella stessa area un ponte nascosto, continuamente vigilato da dieci galee e molti armati ${ }^{8}$.

In seguito ai risultati negativi negli scontri e, soprattutto, all'impossibilità di ricevere soccorso da una nuova armata in arrivo da Pisa, per la presenza della squadra catalana guidata da Pere de Belloch che stazionava nelle acque del porto di Castel di Cagliari, la città non poté continuare a resistere e iniziarono così le trattative di pace con gli Aragonesi che si conclusero il 19 giugno del 1324 con la firma di un accordo 9 . In virtù di questo trattato i Pisani mantenevano sotto forma di concessione feudale dagli Aragonesi il controllo di Castel di Cagliari con le appendici di Stampace, Villanova, il porto, lo stagno di Santa Igia, ma erano costretti a cedere ai vincitori le saline e la gran parte del regno, perdendo le basi su cui si fondava la loro ricchezza ${ }^{10}$. Le condizioni stabilite pertanto, piuttosto che placare gli animi, creavano le premesse per una nuova ripresa del conflitto. D'altro canto l'infante, convinto di avere raggiunto una conquista sicura, nel luglio del 1324 lasciava l'isola.

e dalla presenza di una cisterna. Sul monumento eretto a memoria della vittoria: A.M. ARAGó CABAÑAS, Un monumento conmemorativo de la batalla de Lucocisterna, in Studi storici e giuridici in onore di Antonio Era, Padova, 1963, pp. 1-10.

${ }^{8} \mathrm{~L}$ 'interessante descrizione di questi eventi si trova nella Cronaca di Pietro IV, cfr. G. MELONI, L'Italia medioevale, cit., p. 57.

${ }^{9}$ Il documento è stato edito da A. Arribas PalaU, La conquista, cit., II, doc. XLVI, pp. 415-420. F.C. CASUla, La Sardegna, cit., pp. 175-177. Sugli accordi: IDEM, I trattati diplomatici sardo-aragonesi del 1323-1326, in Sardegna, Mediterraneo e Atlantico tra Medioevo ed età Moderna. Studi Storici in memoria di Alberto Boscolo, a cura di L. D’Arienzo, I, Roma, 1993, pp. 207-220.

${ }^{10} \mathrm{M}$. TANGHERoni, Alcuni aspetti della politica mediterranea di Giacomo II d'Aragona alla fine del suo regno, in "Annali delle Facoltà di Lettere, Filosofia e Magistero dell'Università di Cagliari", XXXII (1969), pp. 138-139, e M.E. CADEDDU, Giacomo II d'Aragona, cit., p. 289. 


\section{LO SVILUPPO URBANO DI BONARIA}

L'importanza di difendere i risultati ottenuti sul campo e il desiderio di creare un centro mercantile in aperta concorrenza con Castel di Cagliari, avevano spinto Alfonso a favorire una politica di rapido sviluppo dello stanziamento in Bonaria, nella speranza di provocare la crisi economica e l'abbandono definitivo del castrum da parte dei Pisani" ${ }^{\prime \prime}$ Già nell'aprile del 1324 l'infante aveva ordinato a Bernat de Boixadors di attribuire a Guillem Gavarra e Francesc Alfons Remolar un hereditamentum prope castrum de Bonayre per costruire un hospicium e ivi trasferire la propria residenza; il 20 settembre dello stesso anno si concesse un terreno anche a Bernat Arbocet $^{12}$.

Effettivamente le cronache catalane non sono concordi nello stabilire i tempi e i modi della nascita dello stanziamento aragonese sulla collina di Bonaria, attribuendo di volta in volta ad Alfonso, a Francesc Carrós, a Guerau de Rocabertí l'inizio dei lavori, ma alla luce dei documenti finora conosciuti sembrerebbe spettare proprio all'infante la scelta del luogo che sarebbe stato, seppur per breve tempo, la prima capitale del regno di Sardegna ${ }^{13}$.

\footnotetext{
"M. TANGHERONI, Alcuni aspetti, cit., doc. IX, pp. 162-166 (ACA, C, reg. 424, ff. 14r19v). Nel maggio del 1325 l'infante si esprimeva così a proposito del popolamento di Bonaria (ibidem, f. 19v): «Item cum dominus Infans intellexerit quod administratores predicti contenderunt et contendunt cum hominibus qui volebant populare in Bonayre propter censum et laudimium quod petebant nimium propter quod ad partes istas multi ex dictis populatoribus remearunt, mandat dominus Infans quod a modo non contendant cum populatoribus pro aliquo censu, laudimio et fatica, quare dominus Infans non intendit nisi ad hoc solum ut locus de Bonayre totaliter popularetur".

${ }^{12}$ ACA, C, reg. 392, f. $197 \mathrm{v}$; reg. 390, f. $174 \mathrm{r}$

${ }^{13}$ R. MUNTANER, Crònica, cap. CCLXXIV: «E puis ven-se'n (Alfonso) en Càller, e edificà davant lo Castell de Càller un castell e una vila, e mès-li nom Castell de Bonaire»; ma lo stesso autore si contraddice e, poco più avanti, afferma che Francesc Carrós iniziò i lavori del castello di Bonaria, sfruttando come manodopera anche le ciurme di alcune galee pisane catturate (ibidem, cap. CCLXXXIV): «E aquells trenta (Pisani), pus fos jorn, quel els trobaren vius, no els mataren, que l'hom, pus és pres, no és vassallatge que hom l'alcia; mas tantost los foren fets gambals de ferre, e mès-los a l'obra del mur e del vall que l'almirall (Francesc Carrós) feïa fer al dit lloc de Bonaire, qui en poc de temps s'és fet dels bells llocs que anc hom pogués veure fet en deu tants de temps. Que vull que sapiats que en aquell temps se trobava que hi havia més de sis mília hòmens d'armes bons, tots catalans, ab llurs mullers, e no havia dos anys que el dit almirall lo començà a edificar, con tenia assetjat lo Castell de Càller e el senyor Infant n'Anfós tenia assetjada Viladesgleies». Secondo la cronaca di Pietro IV invece, sarebbe stato Guerau de Rocabertí a costruire le prime opere in Bonaria: G. MELONI, L'Italia medioevale, cit., pp. 44-45: «lo noble En Guerau de Rochabertí, e ab aquells qui ab aquell eran al loch de
} 
Sin dal $1^{\circ}$ luglio del 1324 infatti, l'erede al trono aveva concesso ai baroni, cavalieri, ufficiali, mercanti e soldati di disporre in libero e franco allodio delle domos et barracas che erano state costruite nella villa ${ }^{14}$. Inoltre proseguivano i lavori di fortificazione del castello: si era costruita una muraglia larga 20 palmi, comprendente il complesso religioso di San Saturno, una torre in direzione del porto e un antigor de banys, cioè le rovine di strutture termali romane. A protezione della villa erano stati approntati anche due valli e nello spazio ivi compreso scorreva l'acqua dello stagno che confluiva nel mare ${ }^{15}$.

Quart, porien posar setge al Castell de Càller. E axí fon fet que.s posaren denant lo dit Castell, en I puig qui ha nom Bonayre, lo qual muraren e enfortiren». G. ZURITA, Anales de la Corona de Aragón, I. II, VI, c. 61. In realtà se la scelta di Bonaria fosse precedente all'arrivo di Alfonso non si spiegherebbe perché costui, giunto nel Cagliaritano dopo la conquista di Iglesias, stazionò per vari giorni a Selargius, una località distante poche miglia da Cagliari, quando, in tal caso, avrebbe potuto sostare direttamente in Bonaria (cfr. A. ARriBAS PALAU, La conquista, cit., pp. 233-234).

${ }^{14}$ ACC, Sez. Antica. Pergamene, n. 22, regestata da S. LIPPI, L'Archivio Comunale di Cagliari, Cagliari, 1897. pp. 123-124. Lo stesso giorno Alfonso concedeva a Nicolau Manyet la carica di guardia della darsena di Bonaria: ACA, C, reg. 390, f. 137v. Sul rapido popolamento della villa si veda anche R. MUNTANER, Crònica, cap. CCLXXVIII.

${ }^{15}$ A. Arribas Palau, La conquista, cit., pp. 340-ss. e G. TODde, Castel de Bonayre, cit. p. 336. E interessante ricordare che il documento suddetto cita la realizzazione di un mur de tàpia. si tratta del più antico documento di epoca catalana finora conosciuto che faccia riferimento alla tecnica edilizia tradizionale dei muri realizzati con mattoni di fango seccati al sole (in sardo ladiri). Una conferma si trova nelle fonti che parlano della realizzazione delle opere difensive di Bonaria, come il libro dei conti di Felip de Boï (ACA, RP, MR, reg. 2059, f. $5 r$ ) in cui si fa anche riferimento ai tapiadors, i maestri muratori esperti di tale tecnica. Il più recente contributo su questo tema si deve a M.E. CADEDDu, P.F. Simbula, R. SANnA, Adobes, ladiri et tapies. Sources litteraires et archivistiques pour l'étude de l'architecture en terre crue de l'île de Sardaigne, in L'Architecture de Terre en Mediterranée. Histoire et Perspectives, Colloque International (Rabat 1996). D'altronde già una delle carte sarde edite da A. SoLMI, Studi storici, cit., pp. 393-ss., ricordava $\mathrm{i}$ «maistros in pedra et in calcina, et in ludu et in linna", tale fonte è citata da F. ARTIZzU, Note sulla casa sarda nel Medioevo, in Società e istituzioni nella Sardegna medioevale, Cagliari, 1995, pp. 25-34. Su questa tecnica edilizia si veda il volume curato da A. SANNA, Architetture in terra. Tipologia tecnologia progetto, Cagliari, 1993. Varie testimonianze inedite di epoca catalana sull'uso delle tapies, che permettono anche di individuare un gruppo di tapiadors operanti a Castel di Cagliari fra Trecento e Quattrocento, sono state studiate: M.B. URBAN, Cagliari catalano-aragonese. Topografia e insediamento nei secoli XIV e XV, tesi di Dottorato di Ricerca. Sulle fortificazioni erette nel colle di Bonaria, oltre al lavoro già citato di G. Todde, si vedano G. MELONI, L'Italia Medioevale, cit., p. 55; A. ARRIBAS PALAU, La conquista, cit., pp. 340-ss. e R. MUNTANER, Crònica, cap. CLXXIV, citato in E. PUTZULU, La prima introduzione del municipio di tipo barcellonese in Sardegna. Lo statuto del Castello di Bonaria, in Studi storici e giuridici in onore di Antonio Era, Padova, 1963, p. 325. nota 6. L. D'ArIEnzo, San Saturno di Cagliari e l'ordine militare di San Giorgio de Alfama, in "Anuario de Estudios Medievales" (d'ora in avanti "AEM"), 11 (1981), p. 831. 
L'opera di fortificazione proseguì nel corso del 1325 e sicuramente agli inizi dell'anno successivo, infatti varie fonti inedite permettono di ricostruire, seppure in linea generale, la successione degli interventi. Nel luglio del 1325 Alfonso attribuì l'incarico di obrer con un salario annuale di 1500 soldi genovini a Guillem de Cornalboix ${ }^{16}$, ma il mancato ritrovamento del suo prezioso libro dei conti ci impedisce di avere informazioni precise sul tipo dei lavori compiuti, sappiamo soltanto che si occupò di diverses obres e la spesa ammontò a 2893 lire 5 soldi 7 denari alfonsini minuti.

Successivamente, su ordine regio, il consiglio della villa di Bonaria e Arnau de Cassà, amministratore generale del regno di Sardegna, attribuirono la direzione dei lavori de I partida de la obra del mur de la dita vila a Jaume Axado. Si trattava di intervenire lungo il lato costiero e di approntare, tra l'altro, un portal de pedra nei pressi della chiesa di Santa Maria del Porto $^{17}$. Jaume iniziò ad operare il 31 luglio, avvalendosi della collaborazione del maiorchino Salvador Espanya per la contabilità, e proseguì fino al 5 ottobre; il resoconto delle spese compiute raggiunse la cifra di 11262 soldi 5 denari alfonsini ${ }^{18}$. In seguito alla rinuncia dei due incaricati, Francesc Carrós dovette nominare un nuovo obrer e scelse Guillem Rovira, che operò fino al 28 gennaio del 1326 e si occupò, in particolare, della costruzione

\footnotetext{
${ }^{16} \mathrm{ACA}, \mathrm{RP}, \mathrm{MR}$, reg. 2059, ff. 13v-14r. Prima di ricevere l'incarico di realizzare le opere del castello di Bonaria, Guillem Cornalboix, che era originario del Rossiglione (M.M. COSTA I PARETAS, El santuari de Santa Maria de Bonaire a la ciutat de Càller, Cagliari, s.d., p. 7), aveva diretto i lavori per la costruzione di una verdesca a Capoterra, «ço és, entre la mar e l'estany del Castell de Càller» (ACA, RP, MR, reg. 2059. f. 14r) dal 23 aprile al 31 maggio 1324. Per diretta volontà di Alfonso ottenne il titolo di obrer di Bonaria e successivamente la nomina gli venne confermata per Castel di Cagliari (ACA, C, reg. 508, f. 150r). Sappiamo che ricevette 9 lire 17 soldi 11 denari per il restauro della torre di San Pancrazio e altre 80 lire 2 soldi per alcune opere compiute (ACA, RP, MR, reg. 2064, f. 2 Ir e f. 18r).

${ }^{17}$ Vedi nota 65.

${ }^{18} \mathrm{ACA}, \mathrm{RP}, \mathrm{MR}$, reg. 2059, f. 4r-v. La fonte afferma che Jaume Axado ricevette la nomina di obrer e pagador. Nella direzione delle opere venne affiancato da Salvador Espanya, un mercante maiorchino che nel luglio del 1324 aveva ricevuto l'incarico di dirigere l'ufficio dei pesi e delle misure di Bonaria, ma l'anno successivo, per ordine del governatore Francesc Carrós e dell'amministratore generale Arnau de Cassà, ottenne l'incarico di upagador e sobrastant de I partida de la obra del mur de Bonayre" con un salario di 3 soldi diari. In effetti nella registrazione relativa a Salvador Espanya si afferma che tale partita dei lavori iniziò non il 31 , bensì il 17 luglio e fu conclusa il 5 ottobre dal Rovira (ibidem, ff. 7v-ss.). Alle opere contribui anche il responsabile della darsena, Nicolau Manyet che, tra l'altro, si occupò de recupero del legname necessario (ibidem, ff. $22 \mathrm{r}-23 \mathrm{r}$ ), tra cui quello utilizzato precedentemente dal Cornalboix per la costruzione di una verdesca a Capoterra. Sulla sua attività e gli interventi registrati nei suoi libri contabili si veda ACA, RP, MR, reg. 2059, ff. 22r-ss.
} 
della torre de l'Esperó. Sotto la sua direzione il costo delle opere lievitò fino a raggiungere la cifra di 53587 soldi 8 denari alfonsini ${ }^{19}$.

Mentre i lavori di difesa del castello proseguivano, all'interno delle mura fervevano le opere religiose, per la realizzazione di una chiesa parrocchiale $^{20}$, e quelle civili. Era espresso desiderio dell'infante costruire un edificio per ospitare il capitano del castello di Bonaria e nei suoi pressi sarebbe dovuto sorgere un carcere più ampio di quello esistente ${ }^{21}$. In effetti sappiamo che Arnau de Cassà aveva anticipato un'ingente somma per la costruzione della curia regia, ma successivamente la struttura venne riscattata dalla corte e scelta quale dimora stabile degli Ebrei di Castel di Cagliari e Bonaria $^{22}$. Intanto si era accesa una disputa tra Guillem Oliver, console dei Catalani ${ }^{23}$, e Joan de la Geltrú, apothecarius barcellonese allora residente in Bonaria ${ }^{24}$. Costui era proprietario di un hospicium nel castello di Bonaria, che il console aveva ripetutamente tentato di sottrargli per adibirlo a loggia dei mercanti, ma Alfonso, su richiesta di Joan, ordinò a Berenguer Carrós, capitano in regno Callari, di difendere la proprietà del supplicante contro le ingiuste pretese dell'Oliver. La corte dovette intervenire più tardi sulla stessa questione, confermando l'esigenza di approntare al più presto un

${ }^{19} \mathrm{ACA}, \mathrm{RP}, \mathrm{MR}$, reg. 2059, f. 5r-v; reg. 2064, f. 17. Il salario ottenuto per messio a la torre fu di 27 lire 1 soldo 11 denari: M.M. COSTA I PARETAS, El santuari, cit., pp. 10-ss.

${ }^{20} \mathrm{La}$ chiesa doveva essere già finita nell'aprile del 1325 . Si tratta di una piccola struttura mononavata, con abside pentagonale $\mathrm{e}$, in origine, con copertura lignea, oggi intitolata alla Vergine di Bonaria, protettrice dei naviganti e oggetto di un culto particolare da parte dei Sardi. L'edificio è affiancato da una torre campanaria molto simile a quelle costruite nello stesso periodo a Barcellona. La documentazione relativa alla sua edificazione si trova in M.M. CoSTA I PARETAS, El santuari, cit., pp. 9-ss.; R. SERRA, Il santuario di Bonaria in Cagliari e gli inizi del gotico catalano in Sardegna, in "Studi Sardi" (d'ora in avanti "SS"), XIV-XV (1958), pp. 333-354.

${ }^{21}$ M. TANGHERONI, Alcuni aspetti, cit., doc. IX, p. 166: "Item cum locus de Bonayre remanet, Domino attente et continue suscipiat incrementum, mandat dominus Infans quod constituatur locus congruus in quo sit curia capitanis et iuxta illam fiat locus pro carçellario qui sit aptus, quod ut intellegit dominus Infans locus in quo modo capti custodiunt // est multum angustus. Et ordinat dominus Infans quod si carcerarius de Bonayre recipit immodeatum carcellagium, quod a modo quilibet captus non solvat pro carcelagio nisi tres denarios alfonsinorum minutorum sive multum steterit carcere sive parum».

${ }^{22} \mathrm{La}$ somma anticipata per l'opera da Arnau de Cassà era di 1931 lire 18 soldi 3 denari (ACA, C, reg. 509, f. 103r). La consegna dell'immobile agli Ebrei è in ACA, C, reg. 403, f. $113 r$, ff. $146 v-147 r$.

${ }^{23}$ Sappiamo che Guillem Oliver ottenne da Alfonso la carica di carceriere del castello di Bonaria con un salario pari a 20 fiorini d'oro annui (5 novembre del 1324): ACA, C, reg. 390 , f. $216 \mathrm{v}$.

${ }^{24}$ Sulla loggia dei mercanti: ACA, C, reg. 374, f. 115r (25 settembre 1325, Barcellona). 
hospicium et lotgia et platea ipsius lotgie ${ }^{25}$. L'infante aveva inoltre offerto tre patua a Guillem Jordà, rettore della parrocchia di Bonaria, per costruire la sua dimora, un cimitero e il terzo da sfruttare come vigneto ${ }^{26}$.

Uno degli elementi essenziali del progetto di espansione di Bonaria era costituito dal rafforzamento dell'antico porto del sale, infatti non soltanto nel settembre del 1325 Alfonso ordinava al Boixadors di favorire il popolamento, ma soprattutto rivendicava la necessità di eliminare la palizzata e la torre del porto della Lapola, in cui le barche preferivano attraccare per la sicurezza del $\operatorname{sito}^{27}$. Tale provvedimento rappresentava un esplicito tentativo di indebolimento del porto della Lapola con il fine di rovesciare la supremazia di Castel di Cagliari a tutto vantaggio dell'area di Bonaria. Effettivamente il programma di Alfonso aveva un accentuato carattere antipisano, per alcuni versi discordante con le aspettative che la colonia iberica nutriva, infatti i numerosi privilegi concessi dalla corte avevano alimentato una rapida affermazione delle attività economiche della villa, così che i nuovi venuti pensavano di stabilirsi definitivamente nel nuovo centro ${ }^{28}$. Ma non solo: per accelerarne lo sviluppo, l'antico accampamento, che ora richiamava le genti iberiche con sogni di arricchimento rapido e sicuro, ricevette lo status giuridico di municipio autonomo (10 agosto del 1325) e successiva-

\footnotetext{
${ }^{25}$ ACA, C, reg. 375, f. 68bisr-v.

${ }^{26}$ Conosciamo la conferma della concessione del 4 maggio 1325 (ACA, C, reg. 342, ff. 363r-365r), che si riferisce ad una carta di poco precedente, datata 13 aprile del 1325 .

${ }^{27} \mathrm{ACA}, \mathrm{C}$, reg. 424, ff. 31r-33v (1325 settembre 22, Saragozza), f. 33r-v: «Encara volem e us manam que, com les galeas d'En Pujades sien juntes ab vós, que fassats tot vostre poder per gran servey nostre que desfassets la pal-lissada de Castell de Càller, cor si era desfeta no·y starien tan segurs lenys ne barches poques; encara que si era desfeta ab barches vedaríets a aquells del Castell qui davallen a la torreta prop la Lapola, la qual torreta fets en guisa // que.s desfassa, gran don n'avé soptosament, e fets en tota guisa que en lo port de Bonayre que - $s$ faça paliçada». Su alcuni aspetti legati al commercio attivato nel porto di Bonaria si veda in particolare il memoriale di Alfonso diretto a Bernat de Boixadors, in cui l'infante si compiace della crescita delle attività economiche presso la villa catalana: ACA, C, reg. 424, ff. $20 \mathrm{r}-22 \mathrm{r}$ (18 agosto 1325). D'altronde l'importanza delle strutture portuali in Bonaria era stata già dichiarata dall'infante nel memoriale diretto al re Giacomo dopo la firma del primo trattato di pace: M. TANGHERONI, Alcuni aspetti, cit., p. 152 e M.E. CADEDDU, Giacomo II d'Aragona, cit., pp. 286-ss.

${ }^{28}$ Sulla volontà politica più che su un naturale sviluppo dell'insediamento pone l'accento: E. Putzulu, La prima introduzione, cit., pp. 326-327, seguito da M.R. CONTU, Bonaria roccaforte catalano-aragonese. Quale natura giuridica?, in "Quaderni bolotanesi", 12 (1986), pp. 136-ss.
} 
mente la sua guida venne affidata a un veguer ( 8 maggio del 1326$)^{29}$. In quell'occasione il capitano di Bonaria, fino ad allora suprema figura istituzionale del castello, ricevette il nuovo incarico, uniformandosi agli obblighi spettanti al suo modello barcellonese. Comunque l'infante, secondo il proprio piano, affidava appena pochi giorni dopo a Ramon de Montpaó la carica di veguer di Castel di Cagliari con il salario e gli oneri spettanti secondo la consuetudine ispana ${ }^{30}$.

Intanto Alfonso, così come affermava in un memoriale diretto a Francesc Carrós, continuava a sostenere la crescita edilizia del castello di Bonaria, appoggiando il progetto per la costruzione di un nuovo fossato che sarebbe partito dalla porta que dicitur de l'Amirall usque ad salinas ${ }^{31}$. Accanto alle opere difensive si trattava di creare le condizioni materiali perché una comunità potesse risiedere stabilmente nella villa e la mancanza di un adeguato sistema idrico costituiva un problema da risolvere con urgenza. Per questo motivo era stata costruita una magna et pulcra sisterna, ma senza provvedere alla canalizzazione dell'acqua piovana e ciò rendeva l'opera in gran parte inutile: «non est provisum unde pluvialis aque decurrat ad ipsam... (cisternam)». L'iniziativa non poteva che suscitare lo stupore e l'indignazione dell'infante, il quale, incredulo dinanzi all'inspiegabile errore tecnico, ordinava di provvedere rapidamente «si verum sit, cum non sit credibile quod aliquis prudens faceret talem deffectum, ad quod, si verum est, provideatur omnino et cito».

L'autosufficienza idrica costituiva in effetti un elemento essenziale, soprattutto in tempo di guerra; a questo proposito Alfonso consigliava di garantire l'estrazione dell'acqua da un pozzo costruito nella villa e sollecitava i mercanti di dotare le proprie dimore di cisterne private, seguendo l'esempio delle case di Castel di Cagliari. A sostegno di coloro invece che abitavano negli edifici prospicienti la platea comuni, ivi si sarebbe dovuta realizzare una magna cisterna, assicurando il rifornimento d'acqua alle singole abitazioni per meatum subterraneum, con un vero e proprio sistema

\footnotetext{
${ }^{29} \mathrm{Le}$ fonti sono in ACA, C, reg. 401, f. 14v, n. 1 e f. $15 \mathrm{r}-\mathrm{v}$. Su queste trasformazioni politico-istituzionali si rimanda a A. BOSCOLO, Le istituzioni pisane e barcellonesi a Cagliari prima e dopo il 1326, in Sardegna, Pisa e Genova nel Medioevo, Genova, 1978, pp. 127-138; E. PuTZulu, La prima introduzione, cit., pp. 321-336, e gli studi più recenti di G. TODDE, Castel de Bonayre, cit., pp. 335-346 e M.R. CONTU, Bonaria roccaforte, cit., pp. 139-148.

${ }^{30} \mathrm{ACA}, \mathrm{C}$, reg. 401 , f. $4 \mathrm{r}-\mathrm{v}$.

${ }^{31}$ Questo passo come i successivi sono tratti da M. TANGHERONI, Alcuni aspetti, cit., doc. IX, pp. 164-165.
} 
di canalizzazione ad uso privato e ciò sarebbe risultato maximum bonum totius ville.

Intanto, per sostenere il popolamento della villa e rafforzare la presenza catalana nel territorio, l'infante proseguiva un'intensa politica di concessioni di beni immobiliari -terreni da edificare o hospicia- all'interno delle mura di Bonaria, ma anche nella zona di competenza del municipio compresa tra i due castelli. Nel luglio del 1325 Ramon Savall aveva ricevuto un terreno nella planicia tra Bonaria e il mare della misura di 20 canne per lato $^{32}$. Sempre nello stesso anno Teresa Gombau d'Entença, moglie di Berenguer Carrós, ottenne alcuni edifici in Bonaria che confinavano su un lato con la platea de la Campana, dagli altri con gli hospicia di Pere de Llibià, di Sanç d'Arades e le muraglie del castello ${ }^{33}$. Al novembre risale inoltre la concessione a favore di Garcia de Loriç, che ricevette un «cellarium curie Castri de Bonaire ... situatum in carraria que itur apud ecclesiam Sancte Marie de Portu et in partim cum carrarie que transitum henc coram covas sumptus (sic) dictum castrum situatas $»^{34}$.

Il nuovo anno (1326) si inaugurò con una serie di donazioni a personaggi che avrebbero dovuto alimentare la crescita economica della villa $^{35}$, basta ricordare che il 15 maggio l'infante concesse a Guillem Barceló varie proprietà sparse nel Cagliaritano e, in particolare, un terreno in latere maris tra il centro catalano e quello pisano, dove poter costruire un

\footnotetext{
${ }^{32} \mathrm{ACA}, \mathrm{C}$, reg. 399 , ff. 58v-59r; Successivamente lo stesso personaggio e il fratello Bertran furono beneficiari di un lotto nella Lapola: ibidem, reg. 403 , f. $47 \mathrm{v}, \mathrm{n} .1$.

${ }^{33} \mathrm{ACA}, \mathrm{C}$, reg. 399 , f. $117 \mathrm{v}$.

${ }^{34} \mathrm{ACA}, \mathrm{C}$, reg. 400 , ff. $141 v-142 \mathrm{r}$. Nel febbraio del 1325 Garcia de Loriç, che era stato maggiordomo dell'infanta Teresa, aveva ottenuto l'incarico dell'ufficio dei pesi nella villa di Bonaria, successivamente Alfonso gli confermò la nomina a Castel di Cagliari e villarum Castri Calleri et villarum consistentium in appendiciis suis (ibidem, reg. 403, f. 214r-v).

${ }^{35} \mathrm{Tra}$ le concessioni ricordiamo quella a favore di Torronsa Mayassendis di Gerona (ACA, $C$, reg. 376, f. 89r-v, 30 gennaio 1326), dei fratelli Ramon, Bernat e Jaume Roig (ACA, C, reg. 400, f. 198r, 16 febbraio 1326), di Pere de Canelles (ACA, C, reg. 400, f. $219 \mathrm{v}, 29$ marzo 1326), di Bonanat Sapera (ibidem, ff. 203v-204r, 28 aprile 1326), di Berenguer de Rivardell (ibidem, f. 219r, 29 aprile 1326), di Jaume Daniort, carpentiere (ibidem, f. 230v, 10 maggio 1326), di un certo Joan, mercante maiorchino (ACA, C, reg. 401, f. 1v, 15 maggio 1326), di Antoni Vaquer, corderius (ibidem, f. 14r, 23 maggio 1326), di Guillem Bonencontre, hostiarius (ACA, C, reg. 400, f. 244r, 25 maggio 1326), di Pere Sasala (ACA, C, reg. 401, f. 36v, 5 giugno 1326), di Bernat Mestre(?), fabbro (ibidem, f. 81v, 22 luglio 1326), di Jaume Descoll (ibidem, f. $111 \mathrm{r}, 1^{\circ}$ agosto 1326), di Pere d'Ars (ibidem, f. 36v, 6 agosto 1326).
} 
laboratorio per la lavorazione del vetro ${ }^{36}$. Per favorire la creazione di una seppur semplice rete di servizi municipali, la corte affidava ai privati la realizzazione delle opere e il loro sfruttamento in cambio del pagamento di un censo. Ramon d'Entença, per esempio, ottenne in concessione i bagni pubblici e il privilegio di costruirne di nuovi insieme con due forni ${ }^{37}$. Questi riferimenti confermano che il nucleo originario della villa era in piena fase di crescita; nonostante ciò, è interessante ricordare come già agli inizi del 1326, quando le opere fervevano a Bonaria, l'infante concedeva anche vari hospicia in Castel di Cagliari e lotti di terreno nell'area della Lapola ${ }^{38}$.

Naturalmente le concessioni costituivano solo un aspetto del processo di normalizzazione della vita del castello di Bonaria e si accompagnavano a un complessivo programma di organizzazione politico-istituzionale del nuovo regno, con la nomina di numerosi ufficiali e la distribuzione degli incarichi amministrativi a uomini fedeli alla corte ${ }^{39}$.

\footnotetext{
${ }^{36} \mathrm{ACA}, \mathrm{C}$, reg. 401 , f. 6r. Da un altro documento risalente al luglio 1326 risulta che lo stesso personaggio ottenne da Alfonso un casalinum «in burgo castri de Agua Frigida». (ibidem, ff. $90 \mathrm{v}-91 \mathrm{r}$ ).

${ }^{37} \mathrm{ACA}, \mathrm{C}$, reg. 401 , ff. $7 \mathrm{v}-8 \mathrm{r}$, f. $8 \mathrm{r}-\mathrm{v}$, ff. $8 \mathrm{v}-9 \mathrm{r}$.

${ }^{38} \mathrm{ACA}, \mathrm{C}$, reg. 400 , ff. $185 \mathrm{r}-186$ r; f. $190 \mathrm{r}-\mathrm{v}$; f. 191 r; ff. $191 \mathrm{v}-192 \mathrm{r}$; f. $194 \mathrm{v}$, n. 1 ; f. $196 \mathrm{r}-$ $\mathrm{v}$; ff. 196v-197r; f. 197r-v; f. 197v (Il registro contiene parzialmente una doppia numerazione, noi abbiamo utilizzata la più recente, perché prosegue in modo uniforme). Tra coloro che ottennero la concessione di un immobile a Castel di Cagliari da parte di Alfonso si segnalano: Francesc Desplà, Bernat de Palau, Pere Oliver, Pere Augustí, Arnau Ferran, Bernat de Boixadors, Ramon de Besalù, Pere Plana, Guillem Desllor e Guillem Sima, che ricevette anche un terreno nella Lapola (cfr. Appendice II).

${ }^{39}$ Abbiamo già ricordato la nomina di Nicolau Manyet a guardia della darsena e quella del veguer di Bonaria (vedi supra, note 12 e 27), ma vennero nominati ad incarichi politicoamministrativi anche Bernat d'Olzet, all'ufficio di scrivania della procurazione regia (ACA, C, reg. 390, f. 178r-v), Guillem Oliver, già console dei Catalani, ora carceriere del castello (ibidem, f. 216v), Bartomeu de Sobirats, quale alguatzir (ACA, C, reg. 399, ff. 65v-66r), etc. Dalle fonti si evince che le funzioni e gli incarichi seguirono strettamente l'evoluzione delle vicende politiche e le intitolazioni subirono numerosi cambiamenti, quale riflesso della situazione fluida dei primi anni di governo catalano. Anche i progetti istituzionali si modellarono seguendo una traiettoria da Bonaria verso Castel di Cagliari, la città divenne il punto focale della vegueria e la sede dei più importanti ufficiali del regno. E interessante inoltre rilevare che le nomine nell'amministrazione regia, in quanto stabilite per volontà sovrana, erano considerate alla stregua di "premi", di compensazioni dovute a servizi resi alla Corona. In tal modo la costruzione istituzionale del regno era strettamente dipendente dal "sistema clientelare" che ruotava attorno alla figura del sovrano; le nomine, così come le concessioni feudali, nonostante i limiti immaginabili di una tale forma di governo, crearono una rete di controllo nel territorio e contribuirono alla costruzione del potere aragonese del regno sardo. Una prova di come questi strumenti venissero assimilati e per certi versi ritenuti intercambiabili, si trova, per esempio, nel caso di Pere Plana, portarius regius: vista la mancata assegnazione di un hospicium a Castel di Cagliari, ottenne la commutazione del bene con la nomina ad un ufficio: ACA, C, reg. 401, f. 88r-v (luglio 1326).
} 
$\mathrm{Al}$ di là dei risultati architettonici raggiunti in Bonaria, ci sembra importante ribadire che le fonti confermano l'impegno diretto di manovalanze provenienti dai regni della Corona. La guida delle opere infatti era stata affidata al magister maior Guillem de Cornalboix, originario di Illa de Vall, che dovette occuparsi anche della distribuzione dei lotti di terreno fra gli abitanti e ricevette un patuum da edificare ${ }^{40}$. Tra i numerosi personaggi iberici impegnati nell'attività edilizia e trasferitisi nell'isola, sappiamo che, per facilitare il loro stanziamento in Sardegna, Guillem, magister opere originario di Maiorca ottenne un terreno ${ }^{41}$ e il pittore barcellonese Bernat de Segura, in procinto di giungere in Sardegna con la moglie, quattro figli e la sua familia, ricevette un patuum per costruire una casa e una bottega ${ }^{42}$.

Mentre la villa vedeva accrescere il numero dei suoi abitanti, ormai raggiunto un accordo finale con Pisa, Giacomo II e l'infante inviavano congiuntamente un memoriale a Bernat de Boixadors e Felip de Boil ${ }^{43}$, in cui si invitavano gli ufficiali e i feudatari a mantenere un comportamento corretto nei confronti dei Sardi perché così questi volontariamente sarebbero venuti a popolare i centri catalani e avrebbero accettato meglio il nuovo governo ${ }^{44}$ :

«E si açò e les altres coses se meten en regla de justícia serà la terra en bon estament e los estranyes y vendran de mellor cor per poblar e per mercadejar. E en açò sia lur estudi, con res no és tant plaent als dits senyors ne de res tan gran servey no'ls poden fer, pus la pau és sinó que la terra sia tornada en regla de justícia e que -ls estranyes e los privats senten la dolçor de la senyoria de la Casa d'Aragó e lo bon regiment de justícia, lo qual la merçè de Déu hi és estat e serà ${ }^{45}$.

La corte sottolineava soprattutto l'esigenza di favorire la crescita della vila nova di Bonaria e il rafforzamento del suo porto, confermando la centralità del progetto edilizio gravitante attorno alla collina, ma allo stesso tempo però si insinuava la possibilità di edificare tutta la costa partendo dal

\footnotetext{
${ }^{40} \mathrm{ACA}, \mathrm{C}$, reg. 401, ff. 30v-31r (26 maggio 1326). Le fonti ricordano che la distribuzione dei lotti avvenne "cum funiello" e il Cornalboix fu assistito nell'opera dal socio Berenguer Bacs. Sulle origini del Cornalboix si rimanda alla nota 16.

${ }^{41} \mathrm{ACA}, \mathrm{C}$, reg. 401, f. 12r-v (17 maggio 1326).

${ }^{42}$ ACA, C, reg. 401 , f. 30r-v.

${ }^{43} \mathrm{ACA}, \mathrm{C}$, reg. 378, ff. 15r-18v. Il memoriale risale al maggio del 1326.

${ }^{44}$ ACA, C, reg. 378 , f. $15 \mathrm{v}$.

${ }^{45}$ Ibidem, f. $17 \mathrm{r}$.
} 
centro catalano in direzione di Castel di Cagliari ${ }^{46}$. D'altronde l'infante aveva già provveduto ad ordinare a Ramon de Montpaó la costruzione di un nuovo insediamento nell'area di portus Comitis (Porto Conte) e nel porto di Torres, fornendo una chiara prova dell'interesse catalano per un rafforzamento dei centri costieri sardi ${ }^{47}$.

Il miglioramento delle infrastrutture nella villa di Bonaria non poteva che accrescere le attese degli abitatori e costituire un forte stimolo per chi era ancora indeciso sul trasferimento nell'isola. Ben presto però alcuni segnali incominciarono a mettere in evidenza che la febbrile attività aveva un carattere temporaneo, in quanto i progetti dell'infante divergevano sempre di più dalle aspirazioni della popolazione. Alfonso riteneva infatti, che la crescita del centro di Bonaria avrebbe costituito una seria minaccia per la sopravvivenza economica di Castel di Cagliari e quindi il suo sviluppo forniva un'attiva resistenza all'operosità dei Pisani, tanto che come suggeriva Giacomo II, il centro catalano avrebbe dovuto chiamarsi Avant Càller ${ }^{48}$. In questo modo si sarebbero poste le premesse per impadronirsi definitivamente della roccaforte pisana, annullando il ruolo antagonistico svolto fino a quel momento da Bonaria.

Come bene aveva previsto Alfonso, la convivenza di due centri in uno spazio abbastanza limitato si presentò in poco tempo insopportabile, mentre pericolosi focolari di rivolta al dominio catalano si erano intanto

\footnotetext{
${ }^{46} \mathrm{Ibidem}$, f. 17v: «Encara és semblant als dits senyors que per ço com lo Castell de Bonayre és vila nova e aprés deu per aquell se és restaurada la isla de Sardenya, que·ls dits En Bernat e En Phelip meten tota lur punya que $\cdot 1$ dit loch se pusca créxer e mellorar e no despoblar. E per ço com ara les gents seran volunteroses de poblar pres la mar al port de Banyayra e si açò era la pobla que s'és començada de la porta de Quart en[trò] al puyg de les forches, lo qual solia aver nom Monte Volpino, no's poria complir ne metre avant perquè sembla als dits senyors que entre que la pobla desús dita aja compliment que a null hom no sia donada pobla defora e que 1 navili faça port là on se sol a Bonayre e que $l$ sarts venguen, axí com solen, ab los carros e ab lurs robes a Bonayre. $\mathrm{E}$ açò mantendrà més Bonayre que res. Que quant a Castell de Càller, entenen los dits senyors que tantost que sia en poder dels desús dits En Bernat e En Phelip, sia feta una trencada al cap del Castell a Sant Branchas en la plassa qui és devan la torra de Sent Brachas (sic), axí que a la dita trencada se fassa mur qui reta Castell al cap de la ciutat, lo qual sia Castell e saloquia en lo qual estia lo castellà ab aquells que volrà. E que en les torres meta aquells que li parrà axí que sien là on estaran les guardes a salvament d'ells. E puys, acabada la pobla de Bonayre se deu continuar la pobla de Bonayre a Càller, per tal que tot sia una ciutat, e a la derreria deu-se poblar aquella part qui és al port de Banyayra per ço com és cosa que tost serà poblada, perquè $s$ deu poblar a la derreria. $E$ açò par faedor als dit senyors. E volen los dits senyors que sia feta una torra al puyg de les forches e axí com havia nom Monte Vulpino, que haja nom la torra de Muntfort».

${ }^{47}$ ACA, C, reg. 401 , ff. $4 v-5 r$.

${ }^{48}$ M.E. CADEdDU, Giacomo II d'Aragona, cit., p. 287.
} 
accesi nell'isola. La ribellione agitata dai Doria fuoriusciti a Savona, nonostante fosse stata sedata con la violenza, non aveva placato gli animi, il malcontento era generale tanto che la città di Sassari giunse a proclamarsi libero comune nel luglio del 1325 e solo dopo faticose trattative si arrivò a un accordo il $1^{\circ}$ giugno del 1326. Vista la situazione critica in cui versava la Corona, i Pisani pensarono fosse giunto il momento di scacciare per sempre i Catalani dall'isola, ma ancora una volta vennero sconfitti in battaglia e le truppe guidate dal Peralta e dal Carròs attaccarono la zona del porto, Stampace e Villanova, assediando direttamente il castrum (gennaio del $1326)^{49}$. A questo punto i vincitori furono disponibili a trattare le condizioni di pace, ma la loro posizione di forza determinò la firma di un accordo che non lasciava scampo, infatti i capitoli stipulati furono ben più pesanti dei precedenti. Una delle conseguenze più importanti dell'accordo, ratificato a Pisa nel giugno del 1326, era infatti il passaggio in mano catalana di Castel di Cagliari ${ }^{50}$. La pace offriva insomma ai vincitori il premio più ambito: «Castell de Càller ... una de les pus nobles joyes de mon ${ }^{51}$.

Il 10 giugno del 1326 con una cerimonia solenne, non appena i Pisani abbandonavano per sempre Castel di Cagliari, i Catalani fecero il loro ingresso trionfale e il vessillo raffigurante i pali rossi in campo oro cominciò a sventolare dall'alto della rocca ${ }^{52}$.

\section{Da Bonaria a Castel di Cagliari}

Non appena i Catalani si impossessarono di Castel di Cagliari, l'attenzione di Alfonso si indirizzò alla sua sicurezza, ordinando la chiusura

\footnotetext{
${ }^{49}$ Su questi eventi: M.E. CAdeddu, Giacomo II d'Aragona, cit., p. 301. F.C. CASUla, La Sardegna, cit., pp. 199-ss. e p. 445.

${ }^{50}$ F.C. CASUlA, I trattati diplomatici, cit., pp. 211-ss. Il documento della pace è in A ARRIBAS PALAU, La conquista, cit., doc. LVII, pp. 445-ss., passavano agli Aragonesi: "... Castell de Càller ab les faldes e pertenencies sues sobre la vila d'Estampax e de Vila Nova $e$ ab los orts segons que ab lo tractament de la pau foren amalonats $e$ ab lo port de quell Castell $e$ ab l'estanyo que es de part d'Estampax.». M.E. CADEDDU, Giacomo II d'Aragona, cit., p. 301.

${ }^{51}$ R. Conde y Delgado De Molina, Castell de Càller, cit., p. 225, n. 20.

${ }^{52}$ F.C. CASUla, La Sardegna, cit., p. 211. Il racconto dell'ingresso solenne a Castel di Cagliari si trova in R. MunTANer, Crònica, cap. CCXC e in ACA, C, reg. 342, f. 314v.
} 
del lato interno delle torri e concentrando il sistema difensivo attorno alla torre di San Pancrazio ${ }^{53}$.

La sensazione che si fosse giunti ad una fase chiave della conquista doveva essere avvertita da più parti, non a caso sia la comunità di Castel di Cagliari che quella di Bonaria inviarono i propri ambasciatori a Barcellona per consigliare al sovrano le decisioni da assumere, tra cui anche la scelta di un preciso piano urbanistico ${ }^{54}$. Come una spossante partita a scacchi, i protagonisti della vicenda avanzarono a corte progetti di investimenti edilizi contrastanti, perché in realtà contrastanti erano gli interessi economici sostenuti.

Dinanzi al re i rappresentanti di Bonaria, Arnau Ladrera e Guillem Oliver, avevano naturalmente intessuto le lodi della villa catalana, confermando la sua rapida crescita in seguito alla realizzazione di un centinaio di nuovi edifici ${ }^{55}$. In conformità alle proposte avanzate dagli ambasciatori, alla fine del mese di luglio Alfonso inviò a Bernat de Boixadors e Felip de Boïl una carta in cui ordinava il rispetto del progetto edilizio in direzione della collina di Montfort ${ }^{56}$. L'infante richiedeva un preciso resoconto sull'avanzamento dei lavori nella zona compresa tra la villa e il capo Sant'Elia, e cioè come procedevano le costruzioni dal lato del rilievo verso il mare. Egli si auspicava una rapida conclusione delle opere e in particolare ordinava di mantenere la individualità della villa e di impedire qualunque edificazione tra i due castelli e, soprattutto, tra Castel di Cagliari e la spiaggia. Punto fermo del progetto era il rafforzamento delle strutture nel settore costiero di

\footnotetext{
${ }^{53}$ A. ARribas Palau, La conquista, cit., doc. LVIII, p. 448.

${ }^{54}$ M.E. CAdeddu, Giacomo II d'Aragona, cit., p. 302.

${ }^{55}$ Come ricorda A. ARribas Palau, La conquista, cit., p. 341, ripreso da G. Todde, Castel de Bonayre, cit., p. 341, gli ambasciatori si soffermarono in particolare sulla presenza di numerosi affioramenti di acqua dolce nell'aria di Bonaria, mentre nell'area costiera verso Castel di Cagliari si trovava solo acqua salmastra, inoltre questo sito, a causa della sua ubicazione in pianura, sarebbe stato difficile da proteggere.

${ }^{56} \mathrm{ACA}, \mathrm{C}$, reg. 401, f. 90r (25 luglio 1326). Un'altra fonte già citata (ACA, C, reg. 378, f. 17v) ricorda che l'infante attribuì al puig de les Forches, ubicato in corrispondenza della collina di MonteVulpinu (attualmente Monte Urpinu) il toponimo di Montfort. In realtà, sulla base delle fonti rinvenute si può verificare che con puig de le Forches si intendeva l'ultima propaggine di Monte Urpinu, quasi un piccolo poggio ubicato tra quello e la collina di Bonaria; fu a questa altura che Alfonso diede il nome di Montfort. Il toponimo di Monte Urpinu si conservò come conferma ASC, AAR, BD8, ff. $21 v-22 r$. Sulla base di un riferimento di G.B. Fara, bene avevano ipotizzato F. SEgni PULvirenti, G. SPIGA, Castel de Bonayre e la politica di Alfonso il Benigno, in El poder real en la Corona de Aragón (siglos XIV-XVI), XV Congreso de Historia de la Corona de Aragón (d'ora in avanti CHCA) (Jaca 1993), I, 5, Zaragoza, 1996, p. 478 .
} 
Bonaria, perché così si sarebbe concretizzato il piano di indebolimento del porto pisano della Lapola $^{57}$. Tali convinzioni trovarono un'ulteriore puntuale spiegazione in un lungo memoriale inviato qualche giorno dopo ai supremi ufficiali del regno ${ }^{58}$. Il programma elaborato prevedeva di estendere l'abitato in modo tale che non ci si avvicinasse a Castel di Cagliari, ma nel caso fosse stata completata la «pobla nova noveylament començada vers lo puyg de Muntfort», si sarebbero concessi nuovi terreni agli abitanti ${ }^{59}$. Ogni ulteriore settore di popolamento comunque sarebbe stato condizionato dalla realizzazione delle opere edilizie nella zona compresa tra il colle di Bonaria, ormai saturo, e la collina di Montfort.

Intanto Alfonso, sempre preoccupato di garantire la difesa di Castel di Cagliari, impartiva precise istruzioni a Bernat de Boixadors e Felip de Boïl su come comportarsi nei confronti degli abitanti pisani ${ }^{60}$. In effetti era consapevole che il modo più conveniente per ottenere tale risultato sarebbe stato quello di evacuare i "pullini" ${ }^{61}$, ma ciò non era previsto dall'accordo, si trattava pertanto di escogitare un sistema per cui alla fine gli stessi Pisani si sarebbero trovati costretti ad abbandonare la città. La tattica adottata fu quella di concedere privilegi commerciali ai soli mercanti catalani nel porto di Bonaria, rendendo impossibile agli sconfitti di proseguire le loro attività in quello della Lapola; per questo scopo - dichiarava apertamente Alfonsoera stata sostenuta anche la crescita della villa. Se tale programma non avesse dato i risultati sperati, allora si sarebbe provveduto ad allontanare coattivamente tutti coloro che fossero stati dichiarati sospetti di tradimento alla Corona d'Aragona. I due sistemi proposti erano certamente diretti allo scopo di realizzare un completo ripopolamento di Castel di Cagliari con elementi iberici. Questo progetto, già chiaramente espresso dall'infante in un

\footnotetext{
${ }^{57}$ Tale progetto, che escludeva, come abbiamo visto (supra, nota 27), l'area della Lapola, era confermato in ACA, C, reg. 401, f. 89v (29 luglio 1326). Cfr. F. SEGNI PULVIRENTI, G. SPIGA, Fortificazioni giudicali e regnicole in Sardegna, in La Corona d'Aragona in Italia (secc. XIII-XVIII), XIV CSCA (Sassari-Alghero 1990), II, 2, Sassari, 1996, p. 831.

${ }^{58}$ Il memoriale (ACA, C, reg. 424, ff. 64v-70r) è stato edito da R. CONDE Y DELGADO DE Molina, Castell de Càller, cit., pp. 195-196.

${ }^{59}$ R. Conde y Delgado de Molina, Castell de Càller, cit., p. 201.

${ }^{60} \mathrm{R}$. Conde y Delgado de Molina, Castell de Càller, cit., pp. 195-196, lo studioso data il documento "circa 3 agosto 1326", ibidem, p. 201.

${ }^{61}$ Il termine pollins indicava nelle fonti catalane i discendenti dei Pisani residenti a Castel di Cagliari, cfr. F. LODDO CANEPA, Note sulle condizioni economica e giuridica degli abitanti di Cagliari dal secolo XI al XIX, in "SS", X-XI (1952), p. 26.
} 
suo memoriale del 12 agosto del 1326 diretto al Boixadors, dove ordinava che «tots heretats en Sardenya qui estan a Bonayre se muden en Castell de Càller, e tenguen casa aqui per mils guardar lo dit Castell. E a aço sien induhits los dits heretats cuvinentment ${ }^{62}$, venne astutamente tenuto nascosto per non provocare malumori, in quanto, come era prevedibile, non avrebbe trovato il favore degli abitanti di Bonaria.

Un nuovo memoriale inviato da Alfonso al Boixadors rivela che il progetto del trasferimento a Castel di Cagliari, nonostante la contrarietà della popolazione, incominciava a prendere corpo. L'infante infatti precisava che l'edificazione dell'area compresa «de fora la porta de Quart entro al puyg de Muntfort» avrebbe dovuto essere completata solo a condizione che l'opera si fosse presentata di facile realizzazione. Se non fossero sorti problemi si sarebbe continuato ad estendere «la pobla ... tro a Muntfort, e d'aqui entro a la mar» in direzione sud fino alla spiaggia, confermando la netta separazione dal settore occidentale del golfo dove sorgeva il Castel di Cagliari e favorendo, in realtà, un rafforzamento delle strutture portuali nell'area del litorale di Bonaria. Se però, assicurato l'insediamento nei pressi della porta da cui si dipartiva la strada in direzione di Quartu, cioè nell'attuale snodo di Via Dante-Piazza Repubblica, fossero sorte difficoltà perché «aquella pobla es en loch desavinent que.s la muntanya a avant que hauria hom molt a esperar abans que la dita pobla fos cumplida, per la qual cosa se puria tant i ara venen molts rebuaven e s'en tornaven no seria bona obra» e tutto ciò "puria esser gran dampnage ${ }^{63}$, si sarebbe cambiato completamente programma. Nel caso infatti, che lo sviluppo edilizio giunto alle ripide falde di Montfort «fos gran empatxament de la pobla major [di Bonaria]», l'infante «mana que sia començada pobla nova de la part della, axi que sia començat un bell carrer lo pus bell, e.l pus ample, e.l pus especios e tot dret, qui partescha de la porta de santa Maria del Port e son puyg tot dret entro a Castell de Càller e sia primerament començada e acabada la pobla de la part deça vers Santa Maria del Port, cor si daven a amdsos los caps, tot hom pendria abans en la part de Càller. E sia fet lo dit carrer deves la porta de Santa Maria de Port riba de la mar, axi que cases hage Ia tira entre la mar e el dit carrer a amunt altra tira de cases per tal que depuys acabat lo

\footnotetext{
${ }^{62}$ R. Conde y Delgado de Molina, Castell de Càller, cit., p. 213, n. 7.

${ }^{63} \mathrm{R}$. Conde y Delgado de Molina, Castell de Càller, cit., p. 211.
} 
dit carrer s'en pogues fer altre e puys altre e altre amunt en tro a Sent Sedorn segons que.ls pobladors vulrien ${ }^{64}$.

Questo passo denso di informazioni costituisce il chiaro segnale del mutamento progettuale in atto. Nell'impossibilità di completare l'espansione nei colli circostanti quello di Bonaria, si sarebbe modificato l'orientamento dello sviluppo edilizio, costruendo prima di tutto una strada bella, ampia, rettilinea, dalla porta di Santa Maria del Porto fino a Castel di Cagliari. Il punto di partenza sarebbe stato uno degli ingressi della villa che doveva il suo nome ad una chiesa sulla cui ubicazione si sono avanzate diverse opinioni, ma verosimilmente dovrebbe essere identificata con quella di S. Bardilio $^{65}$. Come abbiamo già ricordato, nel corso del 1325 era stato approntato un portal de pedra in corrispondenza della chiesa di Santa Maria del Porto ${ }^{66}$, un'altra fonte parla chiaramente di una concessione «in loco castri de Bonayre iuxta portam Beate Marie de Portu» ${ }^{67}$ e un documento chiarisce che l'edificio si trovava riba de la mar $^{68}$ laddove, come attesta una fotografia della zona risalente ai primi anni di questo secolo, sorgeva la chiesa di San Bardilio ${ }^{69}$. La struttura è stata demolita agli inizi del Novecento e, soprattutto con l'opera di bonifica che ha interessato la fascia costiera di Bonaria, l'uomo è riuscito a guadagnare alcune centinaia di metri alle acque; il paesaggio si presenta attualmente molto differente, ma le testimonianze raccolte suggeriscono queste conclusioni.

\footnotetext{
${ }^{64} \mathrm{R}$. Conde y Delgado de Molina, Castell de Căller, cit., p. 197 e pp. 211-212.

${ }^{65}$ Verosimile la ricostruzione proposta da G. Cossu PINNA, La carta pisana del $1^{\circ}$ marzo 1230, primo documento della presenza francescana di Santa Maria de Portu Gruttis, in "Biblioteca Francescana Sarda", 1 (1987), pp. 41-ss. Cfr. D. SCANo, Forma Kalaris, Cagliari, 1934 (ristampa anastatica, 1989), pp. 25-ss.

${ }^{66}$ Una fonte inedita catalana fa riferimento alle spese compiute dalla corte «per la compra de pedra a ops del portal de la vila (di Bonaria) qui és prop Sancta Maria de Port e de aygua y de altres logers e compres necessàries a la dita obra»: ACA, RP, MR, reg. 2059, f. 4v.

${ }^{67} \mathrm{ACA}, \mathrm{C}$, reg. 400 , f. 207r (1326 febbraio 16, Barcellona).

${ }^{68} \mathrm{R}$. CONDE y Delgado De Molina, Castell de Càller, cit., p. 212. Ulteriori conferme dell'ubicazione della chiesa si trovano in altre due fonti aragonesi; la prima, cita esplicitamente la chiesa di Santa Maria de Portu de Bonayre (ACA, C, reg. 403, f. 196v), la seconda, riferisce la presenza di pietre da lancio delle macchine belliche anche «subtus murum de Bonayre qui pretenditur de ecclesia sante Marie de Portu usque ad marem» (ACA, C, reg. 509, ff. 95v-96r).

${ }^{69}$ Una fotografia della chiesa di San Bardilio prima della distruzione è stata pubblicata nel volume Cagliari. Quartieri storici. Villanova, Cagliari, 1991, p. 148. Nei primissimi anni di questo secolo si era pensato ad un ripristino dell'edificio e Dionigi Scano aveva elaborato il progetto, ma l'intervento non venne realizzato.
} 
La chiesa di Santa Maria de Portu Gruttis probabilmente era stata edificata dai Pisani nel corso del dodicesimo secolo nei pressi dello scalo salinifero. Nei primi anni del XIII secolo l'edificio passò all'Opera del Duomo di Pisa ${ }^{70}$, nel 1230 divenne francescano e ancora nel 1263, sotto il controllo dell'ordine mendicante, manteneva il nome di Santa Maria de Gruttis $^{71}$. Le maggiori incertezze sussistono secondo alcuni studiosi a proposito della sua identificazione con un luogo di culto ubicato nell'area di Bagnaria sulla base di due passi del Breve de portus kallaretanus, che ricordano la luminaria annuale celebrata dai mercanti del porto di Kallari e il pagamento di una somma destinata all'opera della chiesa di Santa Maria del Porto da parte dei capitani che approdavano in città ${ }^{72}$. Nonostante siano state proposte diverse interpretazioni ${ }^{73}$, le fonti catalane non lasciano adito a dubbi sulla collocazione di una chiesa con questo nome nella zona di Bonaria e di conseguenza l'identificazione con la chiesa di San Bardilio appare più che plausibile ${ }^{74}$. Sulla possibilità invece che esistesse un edificio omonimo nell'area portuale, nonostante la mancanza di riscontri certi, ci soffermeremo più avanti. Su tale importante questione che riguarda non solo la singola struttura religiosa, ma investe il problema più generale della mappa degli insediamenti pisani, si sta rivelando fondamentale il contributo dell'archeologia, infatti da alcuni anni la presunta chiesa di S. Maria del Porto di Bagnaria, identificata con l'attuale S. Eulalia, è interessata da un'ampia campagna di scavi ${ }^{75}$.

${ }^{70} \mathrm{G}$. Cossu PINNA, Inventari degli argenti, libri e arredi sacri delle chiese di Santa Gilla San Pietro e Santa Maria di Cluso, in S. Igia capitale giudicale, cit., pp. 249-260.

${ }^{71}$ F. Artizzu, L'Opera di Santa Maria, cit., p. 78 e P. Tola, Codex Diplomaticus Sardiniae (d'ora in avanti CDS), I, Torino, 1861 (ed. anastatica, Sassari, 1984), doc. CIII, pp. 380-ss.

${ }^{72}$ La chiesa di Santa Maria del Porto, i pagamenti dei capitani e la luminaria sono citate nei passi XXII e XXIII del Breve, vedi F. ARTIZZU, Gli ordinamenti pisani per il porto di Cagliari. Breve portus kallaretani, estratto da "Archivi e Cultura", fasc. XIII, Roma, 1980, pp. 58-59. Notizie storiche sommarie sulla chiesa in Bonaria in R. CORONEO, Architettura romanica dalla metà del Mille al primo '300, Nuoro, 1993, p. 266.

${ }^{73} \mathrm{C}$ fr. I. PRINCIPE, Cagliari. Le città nella storia d'Italia, Bari, 1981, p. 44.

${ }^{74} \mathrm{G}$. SPano, Guida della città e dintorni di Cagliari, Cagliari, 1861 (ora in ristampa anastatica, s.d.), pp. 304-ss., ricostruendo la storia dell'edificio, identificò la chiesa di San Bardilio con quella di Santa Maria de portu Gruttis.

${ }^{75}$ Recentemente l'area interessata dagli scavi é stata aperta al pubblico e fa parte integrante di un progetto museale che si impernia sulla parrocchia di Sant'Eulalia. I dati finora emersi sono senza dubbio eccezionali e ancora maggiori sono le attese per la prosecuzione dell'indagine archeologica nell'area presbiterale, la cui direzione è affidata alla dott.ssa Donatella Mureddu. 
Secondo il programma di Alfonso, lungo il percorso compreso tra la strada diretta verso il Castel di Cagliari e la costa si sarebbe edificata una prima linea di case, altre strade a questa parallele si sarebbero poi costruite «amunt en tro a Sent Sedorn segons que.ls pobladors vulrien ${ }^{76}$. Lo sviluppo edilizio sarebbe stato caratterizzato da una serie di isolati regolari disposti lungo percorsi paralleli compresi tra la spiaggia e l'area di San Saturno, ad occidente del colle di Bonaria; ma ciò che più sorprende è l'ampiezza di questa area da edificare, l'estrema lucidità progettuale dell'infante che, consapevole dell'attrazione esercitata da Castel di Cagliari sui nuovi popolatori, confermò l'ordine di svolgere tutte le attività mercantili nel porto di Bonaria e fissò il punto di partenza del progetto nel settore orientale e non viceversa, "cor si daven a amdosos los caps, tothom pendria abans en la part de Càller». Nelle intenzioni di Alfonso, se tale progetto si fosse realizzato, l'antagonismo fra i due centri sarebbe venuto meno e $\mathrm{i}$ Catalani avrebbero avuto a disposizione un'unica città di notevolissime dimensioni, proiettata sul mare e dotata di straordinarie strutture portuali, condizioni queste indispensabili per rispondere alle esigenze del ceto mercantile.

Intanto, per sostenere ulteriormente l'immigrazione delle genti iberiche nel regno, Alfonso ordinava di concedere agli abitanti anche le «terres ermes de les vils de Paduli prop Palma e de Pirri e de Sovetrano e encara de Ceboyla del estany a ença ves Santa Elia ${ }^{77}$.

Il progetto avrebbe investito un territorio veramente ampio, ma tra la fine del 1326 e gli inizi del 1327 maturarono le circostanze per cui l'erede al trono poté modificare sostanzialmente i suoi piani, spostando gli interventi edilizi nell'area di Castel di Cagliari ${ }^{78}$.

Il programma di Alfonso soddisfaceva evidentemente gli abitanti di Castel di Cagliari, che avevano inviato i borghesi Nicola e Gaddo Soglia a

${ }^{76}$ R. Conde y Delgado de Molina, Castell de Càller, cit., p. 212, n. 2.

${ }^{77}$ R. Conde y Delgado de Molina, Castell de Càller, cit., p. 213, n. 5.

${ }^{78}$ R. Conde y Delgado De Molina, Castell de Căller, cit., p. 213, n. 7: «tots heretats en Sardenya qui estan a Bonayre se muden en Castell de Càller, e tenguen casa aquí per mils guardar lo dit Castell. E a açò sien induhïts los dits heretats cuvinentment». L'infante Alfonso condivideva il piano di concentrare gli interessi catalani nell'area di Castel di Cagliari, infatti in un memoriale del gennaio del 1327 ordinava a Bernat de Boixadors di accelerare quanto possibile il trasferimento: ACA, C, reg. 424, ff. 79r-80r, in particolare f. 79r: «mana lo senyor Infant qu ells façen tota lur punya que 1 Castell de Càller sia establit de pobladors e de viandes e altres coçes com mils se puga fer e a menys temps, e açò sia fet encontinent». Il documento è stato edito da R. CONDE Y Delgado De Molina, Castell de Càller, cit., p. 216. 
Barcellona ad esporre le loro richieste direttamente al re Giacomo $\mathrm{II}^{79}$, nella speranza di convincere il sovrano della superiorità della loro città; in virtù delle qualità del castrum, a loro dire, sarebbe stato opportuno favorire un suo popolamento con genti catalane, facendo convergere le attività economiche nel porto pisano ${ }^{80}$.

Intanto, mentre le due comunità difendevano i propri contrapposti interessi, la conquista del regno sardo incominciava a rivelarsi molto più precaria del previsto, diventava urgente formulare una scelta chiara e definitiva a favore di una delle città, Castel di Cagliari o Bonaria. Sicuramente a pagare il prezzo più alto di tante indecisioni furono in primo luogo i due centri: Bonaria, dopo aver enfatizzato il proprio ruolo di città-guida nell'avanzata del potere catalano nel regno di Sardegna, avrebbe visto bocciare per volontà regia qualunque ulteriore possibilità di sviluppo, anzi la sua stessa esistenza sarebbe stata sacrificata a vantaggio di Castel di Cagliari. In realtà questa delicata fase di passaggio rischiava di lasciare un segno profondo anche nell'antica roccaforte pisana: dopo la grande crescita registrata fino al momento del conflitto, un malessere diffuso e le difficoltà economiche per la concorrenza del porto di Bonaria erano segnali preoccupanti di una situazione che poteva precipitare ${ }^{81}$. In questo contesto si alimentavano le attese e le paure delle due comunità urbane: portavoci di interessi diversi, anzi opposti, i consiglieri di Cagliari e quelli di Bonaria tentavano di convincere la corte del proprio rispettivo primato. Grande spazio nella decisione finale ebbero però gli ufficiali regi che furono tra i più convinti sostenitori della necessità di concentrare a Castel di Cagliari gli interessi della Corona ${ }^{82}$. Non è un caso che Giacomo II, ripetendo concetti già da loro espressi, scrisse una lettera al figlio in cui considerava impossibile che il locus de Bonayre potesse prosperare anche a causa della scarsezza

\footnotetext{
${ }^{79}$ A. Arribas Palau, La conquista, cit., p. 342; M.E. Cadeddu, Giacomo II d'Aragona, cit., p. 302. Risale al 12 ottobre 1326 (ACA, C, reg. 316, ff. 4v-5v) l'intervento diretto del re affinché si presti fede ai patti firmati con Pisa.

${ }^{80} \mathrm{Sul}$ momento in cui avvenne l'ambasciata possediamo un riscontro in un documento di Alfonso datato 17 settembre 1326, in cui l'infante informa i consiglieri di Castel di Cagliari di aver incontrato i nunzi della città, inoltre comunica di aver preparato una propria ambasceria e di essere in attesa di una risposta: ACA, C, reg. 402, f. $165 \mathrm{v}$.

${ }^{81}$ A proposito dell'evoluzione dell'economia sarda in seguito alla conquista catalana, si veda M. TANGHERONI, Il "Regnum Sardiniae et Corsicae" nell'espansione mediterranea della Corona d'Aragona. Aspetti economici, in La Corona d'Aragona in Italia (secoli XIII-XVIII), XIV CSCA (Sassari-Alghero 1990), I, Sassari, 1993, pp. 65-ss.

${ }^{82}$ Cfr. A. Arribas Palau, La conquista, cit., p. 342.
} 
di rifornimenti idrici e, con evidente preoccupazione, sottolineava come, mentre le sorti del centro catalano vacillavano, anche le condizioni di Castel di Cagliari peggioravano e la città rischiava di spopolarsi ${ }^{83}$. La necessità di garantire un sistema difensivo efficace e la consapevolezza della centralità strategica di Castel di Cagliari in un regno attraversato da pericolosi rigurgiti di violenza, convinsero la corte della necessità di operare una scelta definitiva a favore del castrum pisano, perfettamente attrezzato e di gran valore dal punto di vista tecnico ${ }^{84}$.

Alla fine il partito della catalanizzazione di Castel di Cagliari aveva vinto la sua battaglia e seppure nell'agosto del 1326, durante una solenne assemblea celebrata nella chiesa di Santa Maria di Bonaria, i supremi ufficiali del regno confermavano dinanzi ai prohòmens i privilegi del porto di Bonaria e la centralità del suo progetto urbanistico ${ }^{85}$, iniziava di fatto il tentativo di convincere la popolazione al trasferimento ${ }^{86}$. Però il piano non fu di facile realizzazione, infatti nonostante godesse dell'appoggio della corte, il Boixadors dovette impegnarsi a lungo per stabilire un accordo con i rappresentanti della villa. Agli occhi degli abitanti tutto ciò appariva ingiusto e lesivo dei propri interessi, ma il governatore proseguì comunque secondo le direttive ricevute e il 22 gennaio del 1327, dopo lunghe trattative, le parti firmarono un accordo che stabiliva ${ }^{87}$ :

-I proprietari di un immobile in Bonaria avrebbero riscattato una casa a Castel di Cagliari dello stesso valore di quella già posseduta, ma chi

\footnotetext{
${ }^{83} \mathrm{ACA}, \mathrm{C}$, reg. 316, f. 17r-v (Barcellona, 5 gennaio 1327): «Castrum Callari quasi desertum et despopulatum est quia pisani dereliquerunt». Sulle sorti di Castel di Cagliari si veda M.E. CADEDDU, Giacomo II d'Aragona, cit., p. 301.

${ }^{84} \mathrm{M}$. TANGHERONI, Alcuni aspetti, cit., pp. 120-ss. e p. 148. Lo studioso ha sottolineato come la conquista ebbe il carattere di un'impresa feudale, ma l'assenza di numerosi feudatari dal regno provocò il mancato assolvimento del servizio militare, pertanto in questo contesto il ruolo di Castel di Cagliari divenne fondamentale.

${ }^{85}$ ACC, Sez. antica, Pergamene, n. 32 (20 agosto 1326), regestata da S. LIPPI, L'Archivio Comunale, cit., p. 126.

${ }^{86} \mathrm{La}$ scelta di un completo ripopolamento dell'antica città pisana con abitanti catalani e fedeli alla Corona fu attuata anche a Sassari e ad Alghero: A. ARAGó CABAÑAS, La repoblación de Sàsser bajo Alfonso el Benigno (1330-1336), in VI CHSA (Sardegna 1957), Madrid, 1959, pp. 539-549; G. PALA, Una nota sul ripopolamento di Sassari al tempo di Alfonso il Benigno, in "AEM", 10 (1980), pp. 853-870.

${ }^{87}$ ACC, Sez. antica, Pergamene, n. 26 (22 gennaio 1327), regestata da S. LIPPI, L'Archivio Comunale, cit., p. 125. Sulla fonte si rimanda all'analisi di R. CONDE Y DELGADO DE MOLINA, Castell de Căller, cit., pp. 19-20.
} 
non poteva assumersi l'onere del pagamento, avrebbe ottenuto una dimora a Stampace o un terreno nella Lapola

- Chi era proprietario di più immobili in Bonaria avrebbe potuto acquistarne altrettanti in Stampace in libero allodio

-Si sarebbero assegnati sotto forma di enfiteusi i lotti della Lapola, ma chi avesse ottenuto un terreno non sarebbe stato obbligato a edificarlo - Le concessioni nella Lapola riguardavano lotti di terreno di dimensioni pari a $3 \times 5$ canne di Montpellier in cambio di 8 alfonsini d'argento ${ }^{88}$

- La distribuzione degli immobili di Castel di Cagliari e Stampace sarebbe spettata ai proceres di Bonaria, mentre Bernat de Boixadors in persona avrebbe assegnato i lotti della Lapola ${ }^{89}$.

Dal contenuto dei capitoli si rileva che il trasferimento avrebbe comportato solo parziali interventi edilizi, infatti Castel di Cagliari era una città già perfettamente compiuta, ma non solo, anche l'appendice di Stampace poteva costituire un'allettabile alternativa per i popolatori aragonesi, per cui si poteva abbandonare l'impegnativo e soprattutto costoso progetto di un nuovo centro. Al di là della complessità del piano stabilito comunque, l'aspetto più rilevante dal punto di vista urbanistico era la pianificazione di un borgo costiero esterno al castrum, con la concessione di terreni in enfiteusi. Ciò rafforza l'ipotesi che agli inizi del Trecento la zona non fosse ancora occupata da un nucleo abitato. Ma non solo: il ruolo che il governatore avrebbe svolto nell'assegnazione dei lotti costituisce un evidente segnale del grande interesse della corte di gestire questo processo, i cui risultati sarebbero stati determinanti per il futuro economico del regno. Alfonso infatti sapeva perfettamente, viste anche le buone condizioni delle strutture abitative di Castel di Cagliari, quanto sarebbe stato utile concentrare la sua iniziativa nella Lapola, cioè nel settore strategico per le attività commerciali e portuali; inoltre l'ampio spazio a disposizione facilmente edificabile anche per la natura pianeggiante del suolo avrebbe costituito un ulteriore motivo di richiamo per la popolazione iberica ritrosa ad abbandonare le case di Bonaria. Si trattava insomma di un vero piano di riqualificazio-

\footnotetext{
${ }^{88}$ A. AlCover, Diccionari català, valencià, balear, II, Palma de Mallorca, 1985, p. 899 alla voce cana $(1$ canna $=160 \mathrm{~cm})$.

${ }^{89}$ R. Conde y Delgado de Molina, Castell de Càller, cit., p. 20.
} 
ne del sito, la cui direzione venne affidata al Boixadors, il più importante ufficiale operante nel regno sardo.

L'accordo del 22 gennaio è strettamente connesso con un altro documento non datato ${ }^{90}$. Ivi il governatore tranquillizzava l'infante di avere cacciato i pullini da Castel di Cagliari, che poteva perciò essere popolato senza ostacoli in virtù dei privilegi già concessi alla comunità di Bonaria. Una volta compiuto il popolamento l'ufficiale prevedeva di realizzare «una pobla devant la Pola», distribuendo le porzioni di terreno secondo il regime giuridico dell'enfiteusi e affidando agli abitanti l'obbligo della ristrutturazione o costruzione ex novo del muro della Lapola: così ai piedi del più bel castello del mondo, il re avrebbe avuto uno dei più bei censals del mon$\mathrm{do}^{91}$ ! In perfetta corrispondenza con gli elementi essenziali del piano esposto dal Boixadors, il 6 febbraio del 1327 Alfonso spedì un altro documento fondamentale, in cui presentava le caratteristiche del progetto edilizio da realizzare ${ }^{92}$. L'infante infatti ordinava di popolare «illa planicies que inter Castrum predictum et mare, sicut includitur inter muros qui protenditur ab utroque latere Castri predicti usque ad mare» pianificando la costruzione di «plateas et carrerias quas et quot ac prout ad decorem dicte populacione et opportunitatem habitatorum eius vel ad eam venientium noveritis espedire» e riservando una superficie sufficiente da adibire alla darsena, alla dogana, alla casa del peso e agli altri uffici necessari. Le mura della planicies, inoltre, dovevano essere, se necessario, costruite ex novo nel settore meridionale della pianura, lungo il lido costiero: «ordinando quod murus pridem nunc in parte diruti reedificentur et etiam versus mare si et prout necessarium fore noveritis murus novus ad defensionem dicte

${ }^{90}$ R. Conde y Delgado de Molina, Castell de Càller, cit., pp. 218-ss.

${ }^{9}$ R. CONDE y Delgado DE Molina, Castell de Càller, cit., p. 219: " (Alfonso) ... haura I dels bells castells del mon. E al peu I dels censals del mon...". Non si conosce con esattezza la data del documento, ma si possono trovare alcuni riscontri con altre fonti. Nel punto IX del memoriale il governatore dichiara di avere perduto la carta di concessione di un hospicium a Castel di Cagliari e chiede all'infante un rinnovo dell'atto: R. CONDE Y DELGADO DE MOLINA, Castell de Cáller, cit., p. 221: "Item, me recapte la carta de les mies cases del Castell segons les affrontacions que s'en porta, de les quals en Philip de Boyl me mes en possessio per una carta que yo.n havia, la qual es perduta». In effetti Alfonso gli attribuì un hospicium il 30 gennaio 1327: ACA, C, reg. 403, ff. $1 v-2 v$ (1327 gennaio 30, Daroca). Bisogna sottolineare però che il Boixadors nel suo memoriale parla di "mies cases del Castell", mentre questo documento si riferisce a un solo "quoddam hospicium".

${ }^{92} \mathrm{ACA}, \mathrm{C}$, reg. 403, f. 10v (1327 febbraio 6, Daroca). 
populacione construatur...» nella previsione di un ampliamento del perimetro dell'appendice in modo tale da contenere tutta la superficie da edificare ${ }^{93}$.

\section{IL PROGETTO DI INSEDIAMENTO NELLA LAPOLA}

Nonostante Alfonso premesse per una rapida soluzione delle vertenze, i buoni propositi di popolare Castel di Cagliari con le genti di Bonaria non avevano effetto ${ }^{94}$. Gli abitanti infatti non erano disposti a pagare le cifre richieste per le case e volevano ricevere i terreni della Lapola a titolo franco e non sottoposti a censo. Nel frattempo, per incentivare il trasferimento si concedevano privilegi alla comunità residente a Castel di Cagliari, ma erano necessari nuovi finanziamenti per le opere di fortificazione. Nonostante il popolamento fosse prioritario, il progetto trovò numerosi ostacoli e venne completato soltanto nel $1331^{95}$. Sulla base degli accordi, la città svuotata degli elementi pisani, sarebbe stata completamente popolata da elementi iberici fedeli alla Corona, mentre le genti indigene avrebbero continuato a dimorare nelle ville alle falde del castrum, così come era capitato durante il dominio pisano ${ }^{96}$.

Alla fine del febbraio del 1327 l'infante inviava una carta al governatore in cui, ricordando di avere ricevuto notizia degli accordi raggiunti dal Boixadors con i proceres di Bonaria, confermava la libertà dei traffici nel porto della Lapola e le concessioni di immobili di Castel di Cagliari come elemento catalizzante l'interesse della colonia iberica, ma nonostante ciò avrebbe voluto mantenere l'insediamento di Bonaria salvaguardando le fortificazioni ivi costruite. Era suo desiderio, insomma, popolare Castel di Cagliari e insieme non perdere i risultati raggiunti a

\footnotetext{
${ }^{93}$ R. COnde y Delgado de Molina, Castell de Câller, cit., pp. 222-226. Si collega a questa fonte un altro documento, ibidem, doc. VII, p. 227 (12 febbraio 1327, Daroca), si tratta di una carta diretta al governatore con le credenziali per l'ambasciatore Guillem de Abbadia.

${ }^{94} \mathrm{~A}$. Arribas Palau, La conquista, cit., doc. LXII, pp. 461-ss. Lo studioso data il documento all'estate del 1326, in realtà, come ha dimostrato Rafael Conde, non può essere precedente al febbraio del 1327, dal momento che si fa riferimento all'accordo del 22 gennaio. Un quadro della situazione dell'isola nei primi anni successivi alla conquista in J.F. CABESTANY, Situaciò economica dels catalans a Càller en 1328, in VI CHCA, Madrid, 1959, pp. 579-584.

${ }^{95}$ R. Conde y Delgado de Molina, Castell de Cäller, cit., pp. 20 ss.

${ }^{96} \mathrm{C}$ fr. F. LOddo CANEPA, Note sulle condizioni, cit., p. 41.
} 
Bonaria. Per sostenere questo progetto - che gli eventi futuri avrebbero rivelato impossibile - l'infante ordinava di modificare il nome della torre di Montfort che si stava costruendo sul colle omonimo scegliendone uno pulcrius $^{97}$.

Contemporaneamente Alfonso si compiaceva dell'iniziativa del Boixadors diretta alla costruzione di una condotta nella Lapola, tale iniziativa sarebbe stata utile e avrebbe creato un ambiente amoenus per gli abitanti. Il problema idrico e quello più in generale del controllo delle acque non era infatti, secondario. Alfonso, preoccupato per il defalliment d'aygua in Bonaria, esortava con forza il Boixadors a completare il trasferimento ${ }^{98}$. Nel settembre dello stesso anno scriveva più volte al governatore, approvando le iniziative dell'ufficiale, che intendeva «ducere seu duci facere aquam loci de Decimo vel de Uta vel aliumde per terminum dicti Castri et construhere inibi molendina ad expensas proprias» sfruttando i redditi ricavati dall'uso dei mulini per l'edificazione delle mura della Lapola e suggeriva egli stesso la costruzione di un ponte per i collegamenti con lo stagno di Santa Gilla ${ }^{99}$.

\footnotetext{
${ }^{97}$ Lo stesso giorno l'infante inviava una carta ai probiuomini di Bonaria con cui ordinava il completamento della torre di Montfort e il mantenimento del nucleo abitato in Bonaria: ACA, C, reg. 403, f. 46r-v. Il suggerimento che potrebbe lasciarci un pò stupiti, vista la fragilità della proposta di fronte a un fenomeno di spopolamento del colle che di lì a poco sarebbe stato completo, in realtà ha un valore diverso se si pensa che esce dalla sfera pragmatica per investire un ambito, diciamo pure, culturale: E. GuIDONI, Storia dell'urbanistica in Italia. Il Duecento, Roma, 1989, pp. 320-ss.
}

${ }^{98}$ R. Conde y Delgado De Molina, Castell de Càller, cit., p. 225.

${ }^{99} \mathrm{ACA}, \mathrm{C}$, reg. 403, ff. 205v-206r (1327 settembre 20, Saragozza): «cogitavimus quod si fiat pons in goleta per quam discurrit aquam stagni Callari ad mare portus eiusdem erit augmentum et emolumentum maximum Castro et populis antedictis [delle appendici]" e successivamente ibidem, f. 198r, n. 1 (1327 settembre 22, Saragozza). Anche M. PINNA, Indice dei documenti cagliaritani del Regio Archivio di Stato dal 1323 al 1720, Cagliari, 1903, p. 27, n. 128. Sui mulini nel Medioevo sardo: B. Fols, Diffusione e utilizzazione del mulino ad acqua nella Sardegna medioevale, in "MSR", 10 (1985), pp. 9-28. Il consiglio dell'infante venne ascoltato e il ponte fu effettivamente costruito, ma qualche decennio dopo entrò a far parte dei beni ecclesiastici, infatti in un inventario dell'Arcivescovado cagliaritano del 1365, edito da A. BOSCOLO, Rendite ecclesiastiche cagliaritane nel primo periodo della dominazione aragonese, in "Archivio Storico Sardo" (d'ora in avanti "ASS"), XXVII (1961), pp. 3-62, in particolare p. 35, compare che l'uso de los pasajes de les goletes ab la isleta era stato affidato a Esteve Coni in cambio del pagamento di un censo annuale di 15 lire e 2 soldi. Qualche decennio dopo però la Chiesa dovette difendersi dalle richieste del Consiglio cittadino che rivendicava a vantaggio della comunità il controllo delle "due goletas prope Castrum Calleri mare et stagno» con tutti i diritti connessi; interessanti le ragioni avanzate dall'Arcivescovado e dal Consiglio cittadino: "..reverendissimus dominus archiepiscopus dicebat e asserebat notorium esse in Callero insulam que est inffra duas goletas prope Castrum Calleri mare et stagno circumdatam esse ecclesie callaritane cum ipsis duabus goletas et cum omnibus utilitatibus suis possunt 
Animato dall'interesse di realizzare il nuovo insediamento nella Lapola, contemporaneamente alla carta con cui affermava di essere venuto a conoscenza degli accordi raggiunti a proposito del trasferimento degli abitanti di Bonaria a Castel di Cagliari, l'infante incominciò a concedere hospicia in città e terreni nella zona costiera. Oltre alla conferma di un immobile a favore del Boixadors ${ }^{100}$, nel febbraio del 1327 Guillem Sapera, Llop de Concut, i fratelli Pere, Jaume e Francesc Gualbes, Bernat e Arnau Ballester, Ramon e Bernat Savall, Bernat de Vilardell, Arnau Dusay, Berenguer Guerau, Guillem Olomar, Guillem d'Abadia, Bonanat Sapera, Arnau Mascarò ottennero ciascuno la concessione di unum patuum decens ac sufficiens nella Lapola in compensazione dell'abbandono degli edifici di notevole valore posseduti in Bonaria ${ }^{101}$.

Ben presto però Alfonso procedette ad assegnare anche un ristretto numero di edifici in Castel di Cagliari a persone a lui particolarmente vicine. Pere de Llibià ottenne quattro hospicia nella via dei marinai appartenuti al pisano Neri Moxarif; a Pere Guillem de Folquers fu riconosciuto l'acquisto di un hospicium del pullino Vanni de la Cita del valore di 85 lire genovi$\mathrm{ne}^{102}$; ottennero inoltre la concessione di case nel castrum anche Arnau de Cassà, il sardo Grazia Orlandi, fisicus, e i pisani Maxerono Bonaquisto e

pervenire et illa fuisse possessam cum iuribus suis paciffice et quiete per quadraginta et quinquaginta et centum annos per ipsam ecclesiam calleritanam et sic esse prescripta per ipsam ecclesiam contra quascumque personam pretendentes se in ea ius habere dictis vero venerabilibus consiliaribus contrarium dicentibus et asserentibus ipsam insulam sive goletam esse comunem ne dum omnibus hominibus sed et brutis animalibus ex eo quia dicunt eam esse litus maris pariterque latus ad viam publicam labereque in ea ademprivia venacionum pascuorum nemorum ribagiorum aquarum et alia multa ademprivia..." (ACC, Sez. antica, Pergamene, $n$. 339. anno 1398, regestata da S. LIPPI, L'Archivio Comunale, cit., p. 198). Il 27 novembre del 1545 i consiglieri della città ordinavano a due maestri d'ascia il compito di aggiustare il «pas de la goleta» ormai in rovina: ACC, Sez. I, Diversorum, vol. 281, cc. 22r-23v (regestato da E. Gessa, M. VinCI, Le fonti dell'Archivio Comunale di Cagliari, in S. Igia, cit., p. 299, n. 7).

${ }^{100} \mathrm{ACA}, \mathrm{C}$, reg. 403, ff. $1 \mathrm{v}-2 \mathrm{v}$. La stessa concessione fu ulteriormente confermata nel giugno dello stesso anno: ibidem, ff. 79r-80r.

${ }^{101} \mathrm{ACA}, \mathrm{C}$, reg. 403 , ff. $45 \mathrm{v}-46 \mathrm{r}$; f. 46 ; f. $46 \mathrm{v}$; ff. $46 \mathrm{v}-47 \mathrm{r}$; f. $47 \mathrm{r}$; f. $47 \mathrm{v}$. Il 2 marzo il beneficiario fu Guillem Sima (ibidem, f. 52r); il 5 marzo, l'apothecarius barcellonese Joan de la Geltrú (ACA, C, reg. 316, f. 24r); l'11 marzo, Berenguer Salvador e Francesc Mateu (ACA, C, reg. 403, f. 60r-v), il 21 luglio, Arnau de Cassà (ACA, C, reg. 403, f. 199r-v), il $1^{\circ}$ agosto, Bonanat Sapera e Bernat Despont (ibidem, ff. 158v-159r e f. 169r-v).

${ }^{102} \mathrm{ACA}, \mathrm{C}$, reg. 403 , ff. $73 v-75 v$, f. $97 \mathrm{r}$. 
Lotto Serragli ${ }^{103}$. Una seconda ondata di donazioni si registrò a partire dall'agosto dello stesso anno: questa volta Bonanat Sapera, Guillem Olomar, Bernat Despont, Gallard de Mallol ricevettero beni in città e nelle appendici di Stampace e Lapola ${ }^{104}$.

Accanto alle assegnazioni a favore dei singoli, si progettava intanto l'organizzazione delle infrastrutture e dei servizi nella Lapola dove, nel tratto della via Roma compreso tra la via Baylle e la via Barcellona, continuavano a sussistere le strutture portuali pisane, ma gli ambiziosi progetti catalani prevedevano un loro ampliamento. Alla fine del febbraio del 1327 infatti, l'infante si dichiarava soddisfatto per l'iniziativa del Boixadors che intendeva investire i censi ricavati dalla concessione dei terreni nell'opera di realizzazione della darsena e per il mantenimento di due galee armate nel porto, mentre in una missiva del $1^{\circ}$ agosto precisava con dovizia di particolari le condizioni da rispettare nella realizzazione delle opere ${ }^{105}$. Se l'ubicazione della darsena pisana, di dimensioni ridotte per le insorgenti esigenze mercantili catalane, avesse costituito un impaccio per lo sviluppo dell'insediamento nella Lapola, si sarebbe costruito un nuovo edificio in un sito differente e la superficie su cui sorgeva sarebbe stata divisa e concessa in parti uguali a Bernat de Boixadors, Guillem Olomar, Bonanat Sapera, Ramon Savall. In caso contrario ai quattro fedeli sarebbero stati concessi i terreni precedentemente riservati per l'edificazione dei nuovi uffici e comunque avrebbero ricevuto degli appezzamenti non inferiori alle 10 canne

${ }^{103}$ ACA, C, reg. 403, ff. 104v-105v; ff. 105v-106r; f. 199r-v; ff. 109v-110r; f. 110r, ff. $112 \mathrm{r}-113 \mathrm{r}$; ff. $115 \mathrm{r}-116 \mathrm{r}$. Il medico arborense Grazia Orlandi ottenne, nonostante il divieto vigente per gli stranieri, il diritto di residenza a Castel di Cagliari (ibidem, f. 158r-v). Bisogna ricordare inoltre, che le concessioni interessarono anche terreni coltivati, come nel caso di Bernat Muntaner (ACA, C, reg. 403, f. 110r) e di Bernat Despont (ibidem, f. 110v), costui ottenne un pezzo di terra ubicato prope locum vocatum de Sent Elia, appartenuto al pullino Peruxo Pelissari, ma tale concessione gli venne contestata. Lotto Serragli rivendicó la proprietà di un orto sito in confinibus Castri Callari, per cui Alfonso nominò Galceran Nagera, esperto in leggi, e lo stesso Bernat Despont poc'anzi citato, per dirimere tale vertenza (ibidem, f. 116r, n. 1).

${ }^{104} \mathrm{ACA}, \mathrm{C}$, reg. 403, ff. $158 \mathrm{v}-159 \mathrm{r} ;$ f. $159 \mathrm{r}-\mathrm{v} ;$ f. $171 \mathrm{r}-\mathrm{v}$; f. 179v, n. 2.

${ }^{105} \mathrm{ACA}, \mathrm{C}$, reg. 403 , ff. 44r-45v; ff. 157r-158r. Intanto nel luglio del 1327 si stabilì di conservare il sale nel portico di un hospicium esistente infra clausuram salinarum, mentre il piano superiore sarebbe stato adibito ad ufficio dell'amministrazione delle saline: ibidem, $\mathrm{f}$. 142 r; f. $143 r-v$ 
di lunghezza e 15 di larghezza, ampliando se necessario, l'area prestabilita, con l'annessione di lotti contermini ${ }^{106}$.

La toponomastica ci fornisce un'ulteriore conferma che i provvedimenti poc'anzi ricordati facevano parte integrante di un programma complessivo diretto alla creazione di uno stabile insediamento nella Lapola, il quale, seppur con difficoltà e in un arco di tempo più lungo del previsto, diede $\mathrm{i}$ suoi frutti ${ }^{107}$. Agli inizi degli anni sessanta del Trecento risale infatti l'attestazione di un carrer appellat de Leyda, in cui si trovava il terreno concesso allo stampacino Pere Cauli, mentre in una registrazione del 1373 si ricorda il carrer de Valencia ${ }^{108}$. Ma già da tempo si conoscevano altre due vie ugualmente dedicate a città della Corona d'Aragona e cioè, il vico nominato carrer de Villafranca e il vico nominato de Gerona ${ }^{109}$. Il loro rinvenimento costituisce senza dubbio una prova dell'esistenza di una pianificazione e della forte connotazione politico-culturale impressa dalla corte a tutto il progetto; in questo modo inoltre, confermando un legame molto stretto con la madrepatria, si creava un ambiente familiare per gli immigrati catalani nel regno sardo. Per quanto riguarda l'esatta identificazione di questi percorsi nel tessuto stradale, è certo che si trovavano nei pressi del vico de Barchinona, centro propulsore delle attività economiche del

\footnotetext{
${ }^{106}$ In realtà la costruzione della darsena durò più del previsto, nel 1332 si ordinava di abolire le imposizioni applicate per raccogliere $\mathrm{i}$ fondi da investire per metà nell'edificazione della darsena, se i lavori non fossero stati completati: M. PINNA, Indice, cit., p. 22, n. 92. ACA, C, reg. 403, f. 10v e ff. 157r-158r. Secondo il documento succitato il Boixadors rivestiva il duplice ruolo di pubblico ufficiale e di privato beneficiario della concessione regia: a lui era infatti affidato il compito di giudicare l'adeguatezza o meno delle strutture esistenti e la scelta dei lotti di terreno.

${ }^{107}$ Una ricostruzione dello sviluppo della Lapola si trova in M.B. URBAN, Cagliari catalanoaragonese, cit. in cui si analizzano, oltre a quelle qui presentate, tutte le fonti inedite rinvenute. La certezza che l'insediamento in questo settore fu tardo deriva anche dai risultati degli scavi compiuti finora che confermano, limitatamente all'area studiata, la presenza di materiali e strutture, superata la fase tardoantica e altomedievale, solo a partire dal tardo Medioevo: D. Mureddu, F. Porcella, Cagliari-Via Cavour. Nuovi elementi per la storia del quartiere della Marina, in "Quaderni della Soprintendenza archeologica per le province di Cagliari e Oristano», 12 (1996), pp. 95-129.

${ }^{108} \mathrm{ACA}, \mathrm{RP}, \mathrm{MR}$, reg. 2082, f. 16r; ACA, RP, MR, reg. 2083, f. 24v; ACA, RP, MR, reg. 2084, f. 11v. Il carrer de Valencia compare in ACA, RP, MR, reg. 2087, f. 18r e ACA, RP, MR, reg. 2088, f. $20 \mathrm{v}$.

${ }^{109}$ Queste due toponimi sono citati in un documentato del 1371 edito da F. LODDO CANEPA, Note sulle condizioni, cit., p. 105 , in cui si parla anche della chiesa di Sant'Eulalia. In realtà si tratta della conferma di un atto risalente al 1368.
} 
quartiere che ancora oggi mantiene il suo nome originale ${ }^{110}$. Questa via partiva dal molo per raggiungere la parte settentrionale del quartiere ed era tangente all'antica chiesa di Santa Lucia, probabilmente uno degli elementi generatori dell'abitato, ubicato a brevissima distanza dalla chiesa di Sant'Eulalia, le cui pertinenze si affacciavano sulle vie di Villafranca e di Gerona. Nonostante una certa imprecisione, si può quindi riconoscere nel perimetro compreso fra la via Roma, la via Baylle, la via Lepanto e la via Manno il cuore del borgo marinaro catalano ${ }^{111}$.

Il desiderio di realizzare al più presto il popolamento nell'area costiera veniva inoltre sancito da Alfonso con l'ordine di «erigi et dotari in Lapola Calari in certi loco dicte Lapole» una chiesa dedicata alla Santa Maria della Vittoria dei Catalani per celebrare il successo ottenuto sul campo di battaglia $^{112}$. In realtà tale decisione dell'aprile del 1327 modificava un progetto risalente all'anno precedente, che prevedeva la costruzione di una seconda chiesa da affiancare alla parrocchia di Bonaria, e costituiva quindi un'esplicita conferma della concentrazione degli interventi nell'area costiera di Castel di Cagliari e il contemporaneo abbandono della prima città catalana nel regno di Sardegna ${ }^{113}$. Tale documento, chiaro nei suoi contenuti, ha alimentato numerosi dubbi al momento dell'identificazione dell'edificio religioso. Attualmente infatti non esiste nessuna chiesa dedicata alla Vergine della Vittoria, né le fonti antiche e moderne la ricordano. Forse il progetto si realizzò ma il luogo di culto ricevette una diversa intitolazione. Altrimenti si ristrutturò e si diede un nuovo nome ad un'antica struttura pisana. In tal caso però di quale edificio si tratta? Nonostante l'assenza di precisi riscontri archivistici, ci sembra lecito avanzare un'ipotesi. È possibile che dietro la misteriosa intitolazione di Santa Maria della Vittoria si nasconda quella di Sant'Eulalia, ancora oggi parrocchia del quartiere della Marina (l'antica Lapola). Tale culto era così radicato in Catalogna che la sua effigie, insieme con lo scudo comitale, accompagnò Alfonso nell'impresa sarda e questi,

\footnotetext{
${ }^{110}$ Su questo toponimo si veda ASC, ANTCa, ANS, notaio Garau, 337, prot. 2, f. $171 \mathrm{r}-\mathrm{v}$ e ff. $195 \mathrm{v}-196 \mathrm{r}$.

"'Vedi F. Loddo CANEPA, Note sulle condizioni, cit., p. 105.

${ }^{112} \mathrm{ACA}, \mathrm{C}$, reg. 403, ff. 61v-62r.

${ }^{113}$ M.M. COSTA I PARETAS, El santuari, cit., docc. 14-16, pp. 34-ss., in particolare p. 36 , in cui Alfonso invita Joan, vescovo di Cagliari, di confermare ad Arnau Carnisser il titolo di rettore della nuova chiesa che si costruirà nella Lapola al posto di quella preventivata nel sito di Bonaria.
} 
riferendo a corte gli eventi della conquista della città di Iglesias, raccontava di avere deposto l'insegna reale e quella della santa in una chiesa cittadina dedicata a Sant Guantí e di avere ordinato l'immediata costruzione di un castello e di una cappella intitolata alla giovane martire ${ }^{114}$.

Limitandoci al nostro caso e tentando una rapida sintesi sulle emergenze religiose pisane nel sito della Lapola, è necessario ricordare che sono attestate le chiese di Santa Lucia ${ }^{115}$, di San Leonardo ${ }^{116}$ e il centro religioso e assistenziale di Sant'Antonio ${ }^{117}$. La presenza di questi luoghi di culto fu incisiva e duratura, influendo in modo determinante anche sulla

\footnotetext{
${ }^{114}$ M.M. COSTa I Paretas, El santuari, cit., p. 7 e A. Torra PÉrez, Reyes, santos y reliquias. Aspectos de la sacralidad de la monarquia catalano-aragonesa, in El poder real en la Corona de Aragón (secc. XIV-XVI), XV CHCA (Jaca 1993), I, 3, Zaragoza, 1996, p. 500: «...per açó la nau en que venguem avia nom de Santa Eulàlia e la galea nostra atretal, e senyera de santa Eulàlia avem levada tota ora per la mar com veníem, e vuy, com nos fo liurada la vila, feem posar, senyor, la senyera vostra ab aquella de santa Eulàlia esemps en I puig qui és dins la força de la vila en una església qui hi és qui ha nom Sent Guantí, entenens que la vostra senyera e nostra no podia ésser en companya mellor ne pus profitosa. E avem ordonat de fer I bel castel en lo dit puig e fer aquí una capella de santa Eulàlia, la qual dotarem bé...». Nel 1332 Pere Català era il cappellano della chiesa iglesiente dedicata a Sant'Eulalia e usufruiva di un beneficio annuale pari a 50 lire alfonsine, si veda ACA, RP, MR, reg. 2060, f. 66r; inoltre ACA, C, reg. 400 , ff. 226r-227r (10 maggio 1326).

${ }^{115} \mathrm{La}$ chiesa di Santa Lucia è ricordata con quella di San Leonardo tra gli edifici visitati dall'arcivescovo Federico Visconti in occasione della sua visita pastorale in Sardegna nel 1263 (P. TOLA, CDS, I, doc. CIII, pp. 380-383). Sulla base di un inventario del 1338 risulta che l'edificio, amministrato dai Vittorini di Marsiglia, faceva parte dei beni del priorato di San Saturno ed era ornato di due altari, di cui uno dedicato a Sant'Antonio, ambedue muniti di palio e tobalia, e dotato di una piccola campana; l'arredo era completato da alcuni testi religiosi, cioè un messale, un libro di epistole e un libro degli offici. La chiesa e il suo arredo sono descritti in E. BARATIER, L'ínventaire des biens du prieuré Saint-Saturnin de Cagliari dépendant de l'abbaye Saint-Victor de Marseille, Firenze, 1959, p. 54.

${ }^{116} \mathrm{La}$ chiesa di S. Leonardo, come ricorda D. SCANO, Forma Kalaris, cit., p. 118 , compariva in un diploma del 12 giugno 1266 (Biblioteca Universitaria di Cagliari, fondo Manoscritti, "Carte Baylle"). L'edificio e l'annesso centro assistenziale dipendevano dall'Ospedale di San Leonardo di Stagno in Pisa finché in seguito alla conquista catalana entrò a fare parte dei beni della Mensa arcivescovile (Cfr. A. BosCOLO, Rendite ecclesiastiche, cit. p. 58). Il complesso confinava con l'omonima via e con un tros de terra tancat, forse lo stesso orto sancti Leonardi ricordato in una fonte più tarda (ASC, AAR, BD8, ff. 9r-10v).

${ }^{117}$ Secondo l'inventario arcivescovile del 1365 più volte citato, risulta che alla diocesi di Cagliari era soggetto anche lo spital e iglésia de Sant Antoni costruito in epoca pisana Cfr. A BosCOLo, Rendite ecclesiastiche, cit., p. 58. Tale edificio, collegato attraverso un portico ad un ospedale funzionante fino al secolo scorso, fu determinante per lo sviluppo dell'insediamento della Lapola. Il complesso è attestato in vari documenti della prima metà del Quattrocento, come in ASC, AAR, BD3, f. 113r-v. Il carrer de Sent Anthoni de Vianes o semplicemente de Sant Anthoni è ricordato in ASC, AAR, BD12, ff. 15v-16r e ASC, ANTCa, ANS, notaio Garau, 337 , prot. 2, f. 203v. D. SCANO, Forma Kalaris, cit., p. 117, ricorda un atto notarile del 1574 , in cui viene citato il portico di Sant'Antonio: descensus hospitali Santi Antoni.
} 
toponomastica ${ }^{118}$. Ma ai tre edifici bisogna aggiungerne un quarto che, come abbiamo già accennato, alimenta molti dubbi fra gli studiosi, e cioè la chiesa di Santa Maria del Porto di Bagnaria. Nessuna fonte specifica esattamente la sua ubicazione, ma è possibile che sia esistita nello stesso luogo dove attualmente si trova la chiesa di Sant'Eulalia, infatti gli scavi finora compiuti nell'area della parrocchia hanno messo in evidenza una straordinaria continuità d'uso del sito dall'epoca romana fino ai nostri giorni, con momenti di profonda trasformazione delle strutture che ancora attendono una completa lettura. Il culto della giovane martire venne sicuramente introdotto in Sardegna in concomitanza della conquista catalana e l'esempio iglesiente ne costituisce una prova inconfutabile. Eppure la chiesa di Sant'Eulalia è ricordata solo in pochissime fonti, e cioè in un inventario arcivescovile del $1365^{119}$, un documento del $1368^{120}$ e in alcune fonti inedite del 1369 che parlano del campanile «de la església de Senta Aulària en mig loch de la Lapola» come uno dei luoghi in cui le guardie svolgevano regolare servizio di ronda, fatto che trova conferma in un atto del 1398, relativo a un soldato impiegato nella difesa del quartiere collocato en vers Sant Eulàlia ${ }^{121}$. Infine, nelle fonti quattrocentesche viene ricordato l'orto e il cimitero di pertinenza della chiesa suddetta, ma nulla più ${ }^{122}$. Sulle origini del luogo di culto però nessuna traccia. In realtà i vari riscontri che confermano l'esistenza di un programma di insediamento nella Lapola, ci spingono a credere che dovette risalire ai primi anni successivi alla conquista anche il progetto di edificare un centro religioso di matrice catalana, per cui la chiesa fu realizzata (o meglio ristrutturata) nel corso della prima metà del Trecento. Viste le premesse non possiamo negare che ci solletica l'idea di poter collegare le vicende della più antica Santa Maria del Porto di Bagnaria e del progetto della Santa Maria della Vittoria con la storia ormai plurisecolare di Sant'Eulalia, ma dobbiamo ammettere che finora non esiste alcun

\footnotetext{
${ }^{118}$ Il toponimo vico de sant Leonardo è attestato nel 1455 in ASC, ANTCa, ANS, notaio Daranda, 254, prot. 3 , f. 59 , e venne modificato in seguito alla costruzione della chiesa di Sant'Agostino, ma l'intitolazione scomparve del tutto solo quando nella seconda metà del XIX secolo la via assunse il nome tuttora in vigore di Ludovico Baylle.

${ }^{119} \mathrm{~A}$. Boscolo, Rendite ecclesiastiche, cit., p. 58.

${ }^{120}$ Vedi supra, nota 109.

${ }^{121}$ ACA, RP, MR, reg. 2086, ff. 154r-ss.; ACC, Sez. antica, Pergamene, n. 333 (1396 gennaio 28, Castel di Cagliari), regestata da S. LIPPI, L'Archivio Comunale, cit., p. 196.

${ }^{122}$ ASC, AAR, BD12, ff. 15v-16r (1445) e BC10, f. 7r (1483).
} 
elemento certo di connessione ${ }^{123}$. Possiamo solo affermare l'assenza di tradizioni o memorie di altri siti religiosi nell'area della Lapola, se si escludono quelli prima ricordati, e l'origine catalana del culto a Sant'Eulalia.

In verità l'idea di una fondazione ex novo dell'edificio appare artificiosa se si considera ciò che la tradizione racconta sulle origini della chiesa di Sant'Eulalia. I Catalani infatti avrebbero impresso il loro sigillo culturale nelle ben note forme gotiche alla preesistente chiesa di Santa Maria del Porto di Bagnaria. Gli ampi interventi seicenteschi compiuti nell'abside avrebbero infine obliterato i resti di fondamenta più antiche, in particolare quelli di una torre prima esterna all'edificio e solo recentemente portata alla luce ${ }^{124}$. In effetti è probabile che la struttura fortificata riemersa durante gli scavi attualmente in corso nella chiesa di Sant'Eulalia sia da identificare con il campanile medievale, in quanto alcune fonti confermano la sua doppia funzione religiosa e militare in epoca aragonese ${ }^{125}$. In tal caso si sarebbe intitolato alla martire barcellonese un luogo di culto più antico almeno in parte trasformato e chiaramente questo intervento acquisterebbe un forte significato politico-culturale ${ }^{126}$. Un caso parallelo è costituito dalla chiesa di San Giacomo di Villanova, infatti una delle ordinazioni dei consiglieri di Castel di Cagliari del 1346 ricorda i lavori di restauro compiuti e l'intitolazione dell'edificio conferma la stretta relazione con la tradizione iberica. Se si potesse verificare un intervento di restauro nella parrocchia di Sant'Anna di Stampace infine, sarebbe possibile confermare un generale programma riformatore mirante ad una più facile catalanizzazione del territorio urbano e delle appendici ${ }^{127}$.

\footnotetext{
${ }^{123} \mathrm{~A}$ favore di una identificazione della chiesa di Santa Maria della Vittoria con quella di Sant'Eulalia della Lapola si erano già pronunciati: F. SEGNI PULviRENTI, G. SPIGA, Castel de Bonayre, cit., pp. 484-ss., che ipotizzavano anche un possibile impiego nel cantiere della Lapola del magister Guillem Clergue, a cui si deve il progetto della chiesa di Tarragona.

${ }^{12-}$ Sulle testimonianze più antiche si veda D. SCANO, Guida della cittì, cit., p. 203.

${ }^{125}$ La prova ci viene dalle fonti catalane citate nella nota 120 , in cui si ricorda il servizio di ronda quotidiano che si svolgeva nella verdesca del campanile di Sant'Eulalia.

${ }^{126}$ Una conferma di questa ipotesi sembra venire dagli scavi in corso nella chiesa di Sant'Eulalia, dal momento che per il periodo considerato non sono emersi elementi per sostenere la costruzione ex novo di un edificio religioso.

${ }^{127}$ M.C. CANnAS, La parrocchiale di San Giacomo di Villanova in Cagliari. Vicende costruttive dal XV al XVII secolo, in La Corona d'Aragona in Italia (secc. XIII-XVIII). XIV CSCA (Sassari-Alghero 1990), in corso di stampa. Sull attività di rivisitazione stilistica delle strutture esistenti nell'ambito dell' «affermazione di una visione iberica degli spazi liturgici e architettonicim si rimanda a R. CORONEO, Fra il pergamo di Guglielmo e la bottega di Jaume Cascalls: arte in Sardegna nella prima metà del XIV secolo, in "MSR", 20 (1996), pp. 387-ss.
} 
Tornando al problema della chiesa di Sant'Eulalia, nel caso si confermasse l'esistenza di un edificio più antico, si dovrebbe stabilire il momento della nuova intitolazione e quali eventuali trasformazioni furono realizzate. Diversamente da quanto sostenuto però, ci sembra credibile che questo progetto sia precedente al restauro di San Giacomo; ammettiamo di non possedere le prove della nostra affermazione, ma la documentazione finora raccolta mostra, nonostante le iniziative dirette anche al popolamento di Villanova e Stampace, il prevalente convergere degli interessi dei vincitori all'indomani della conquista della città nell'area portuale e, d'altronde, la devozione dei Catalani per S. Eulalia era particolarmente forte, visto il suo ruolo di protettrice della città comitale. Comunque, tenendo conto anche degli interventi compiuti nella cattedrale (1326-1330), miranti a ricodificare la chiesa di Santa Maria di Castel di Cagliari secondo segni e stilemi inconfondibilmente rispondenti ai principi del gotico catalano, ci sembra evidente che da parte dei vincitori venne adottato un esplicito programma di propaganda culturale ${ }^{128}$.

\section{CASTEl di CAGliari "CAPUT totius REgni SARdiniaE"}

L'ormai avvenuta proiezione degli interessi della corte a Castel di Cagliari e nel suo porto venne sancita da parte di Giacomo II nell'agosto del 1327 con la concessione dei privilegi di Barcellona ${ }^{129}$. Il famoso documento, noto come Coeterum, riguardava non solo il territorio urbano e le appendici, ma individuava un'area molto più ampia, che potremmo definire «metropolitana», entro la quale le ordinanze regie avevano vigore e specificamente comprendeva le ville di «Sancta Gila, Pirri, Savatrano,

\footnotetext{
${ }^{128}$ Nonostante la mancanza finora di una sufficiente documentazione archivistica, nutriamo la speranza di trovare una risposta ai nostri dubbi negli scavi archeologici in corso nella chiesa di Sant'Eulalia. Propendiamo comunque, sulla base degli elementi finora noti, in una datazione successiva all'aprile del 1327 (quando si ordina la fondazione di una chiesa dedicata a Santa Maria della Vittoria dei Catalani) e precedente al 1346 (quando vennero realizzati i lavori nella chiesa di S. Giacomo di Villanova).

${ }^{129} \mathrm{ACC}$, Sez. antica, Pergamene, n. 39, regestata da S. LIPPI, L'Archivio Comunale, cit., pp. 127-128. Il testo del documento fu ricopiato in una raccolta iniziata già nel XIV sec. e nota col nome Libro Verde che contiene tutti i privilegi della città, edita da R. Dı TuCCI, Il Libro Verde della città di Cagliari, Cagliari, 1925, doc. XXXXI, pp. 145-ss. Sugli aspetti giuridici: A. BosColo, Le istituzioni pisane, cit., pp. 127-138.
} 
Paduli, Palma, Celargio, Quarto toto, Quarto josse, Quarto donico, Cepoyla cum capite Sancta Elia» ${ }^{130}$.

Il sovrano stabiliva un principio di generale equità nella distribuzione delle case e dei terreni, infatti gli immobili di Castel di Cagliari sarebbero stati attribuiti proporzionalmente a ciò che ciascuno possedeva nella villa di Bonaria e in particolare:

- Chi possedeva un bonum et idoneum hospicium in Bonaria, avrebbe ricevuto un immobile con le stesse caratteristiche a Castel di Cagliari

- Chi era proprietario di più immobili in Bonaria, oltre a un hospicium a Castel di Cagliari, avrebbe ottenuto tante altre case quante quelle possedute in Stampace

- Chi possedeva degli hospicia liberi dal pagamento di censi in Bonaria, avrebbe ricevuto altrettanti patua franchi in Lapola

-I lotti di terreno in Lapola sarebbero stati concessi a titolo franco e non inferiori alle dimensioni di $3 \times 5$ canne di Montpellier ${ }^{131}$.

Come si può vedere, facendo un confronto con gli accordi del 22 gennaio, Giacomo si mostrava particolarmente generoso perché, come più volte sottolinea con le sue parole, l'occupazione di Castel di Cagliari e un rapido sviluppo dell'insediamento nella Lapola costituivano delle priorità assolute da agevolare, se necessario, in ogni modo. Le iniziative del sovrano proseguirono nei mesi seguenti con ulteriori conferme dei privilegi alla città e nuove precisazioni del programma da realizzare, con lo scopo di favorire il processo del popolamento ${ }^{132}$.

\footnotetext{
${ }^{130}$ R. DI TUCCI, Il Libro Verde, cit., pp. 145-146. Sul concetto di urbs, suburbium, territorium nella legislazione classica e medioevale: G. MENGOZZI, La città italiana nell'alto medio evo, Firenze, 1973 (ristampa anast. della 2a ed.).

${ }^{131}$ R. DI TUCCI, Il Libro Verde, cit., pp. 150-151. Gli stessi concetti saranno ripetuti nei privilegi concessi dal sovrano: ACA, C, reg. 403, ff. 183r-187v (1327 settembre 17, Barcellona), f. $185 \mathrm{r}$ in particolare.

${ }^{132}$ Alla realizzazione delle opere nell'area di Castel di Cagliari furono attive, così come era capitato a Bonaria, maestranze catalane che, in seguito al trasferimento, concentrarono i loro interventi nel castrum e nelle sue appendici. Due i casi emblematici: Guillem de Cornalboix ottenne nel 1328 l'incarico di obrer di Castel di Cagliari, dopo aver rivestito lo stesso incarico a Bonaria (supra, nota 16). Nel 1335 Bernat Montanys rivendicò il diritto a una compensazione per $i$ danni subiti in seguito al trasferimento, infatti pur avendo operato in vari cantieri in città, in Stampace e Lapola, aveva perso le sue proprietà in Bonaria senza alcun risarcimento. Risentito per il trattamento ricevuto decise di recarsi personalmente a Barcellona e chiedere giustizia al re Alfonso, con l'avvallo e l'intercessione del consiglio cittadino: ACA, C, CR di Alfonso III, caja 21 , c. 2567 . Le carte reali di Alfonso il Benigno sono state studiate da F.C. Casula, Carte reali di Alfonso III il Benigno re d'Aragona, riguardanti l'Italia, Padova, 1971.
} 
In realtà il piano seguito da Giacomo II risultava in parte diverso da quello per cui aveva operato Alfonso. Da parte sua infatti, il sovrano aveva dichiaratamente scelto la parificazione giuridica di Castel di Cagliari con Barcellona, interpretando il popolamento del centro sardo come uno dei tanti esempi di città di fondazione regia, ma così facendo rompeva lo schema di rigido controllo politico che l'infante aveva pensato di stabilire sin dal primo momento ${ }^{133}$; al contrario la benevolenza di Giacomo poteva rivelarsi rischiosa e dannosa, perché le ampie concessioni in materia fiscale avrebbero fortemente ridotto i proventi della corte. Sarebbe sufficiente ricordare come già agli inizi del 1327 l'erede al trono approvava la scelta del Boixadors a favore di una rigorosa distribuzione sotto forma censuale dei terreni nella Lapola, ma astutamente ordinava all'ufficiale di non dare a intendere alla cittadinanza il progetto di non estendere a Castel di Cagliari i privilegi di Barcellona e Valenza ${ }^{134}$. Tale atteggiamento dimostrava la rigida volontà dell'infante di controllare e sfruttare le risorse economiche del nuovo regno, ma soprattutto metteva in evidenza una concezione centralistica e fortemente autoritaria del potere, che di lì a poco avrebbe avuto modo di esprimersi con decisioni istituzionali innovative di ampie conseguenze ${ }^{135}$. Comunque in virtù del fatto di essere in quel momento ancora il sovrano della Corona d'Aragona, Giacomo II ebbe la meglio sul figlio, concedendo alla città e al suo territorio i privilegi barcellonesi. Il Coeterum sanciva pertanto in modo definitivo il difficile e controverso processo di popolamento catalano di Castel di Cagliari.

\footnotetext{
${ }^{133}$ R. Conde y Delgado DE Molina, Castell de Câller, cit., p. 26. Se Bonaria rappresentava il primo insediamento sardo organizzato sulla base di istituzioni catalane (a proposito si veda anche G. TODDE, Castel di Bonayre, cit., p. 339), anche Castel di Cagliari, nonostante la sua tradizione giuridica di matrice comunale, viveva una fase di profondo rinnovamento in seguito all'estensione della legislazione barcellonese nel suo territorio, scelta che era stata determinata dalla necessità di favorirne il popolamento con elementi iberici. La diversità fra $\mathrm{i}$ due modelli urbani era nella concezione stessa del potere, le nuove forme di governo impiantate a Castel di Cagliari si basavano su un sistema giuridico di tipo privilegiato, diretta emanazione della volontà regia, mentre l'organizzazione comunale prevedeva un'attiva partecipazione dei cittadini alla vita pubblica.

${ }^{134}$ R. Conde y Delgado de Molina, Castell de Càller, cit., p. 199.

${ }^{135}$ Sull'intraprendente politica istituzionale di Alfonso si rimanda ad alcuni studi di G. OLLA REPETTO, Gli ufficiali regi di Sardegna durante il regno di Alfonso IV, Cagliari, 1969; EAD., La storiografia sugli ufficiali regi della Sardegna catalano-aragonese e la nascita dell'istituto del governatore nella Corona d'Aragona, in "Archivio Storico Sardo", XXXVI (1989), pp. 105127; EAD., La politica archivistica di Alfonso IV d'Aragona, in La Corona d'Aragona e il Mediterraneo: aspetti e problemi comuni da Alfonso il Magnanimo a Ferdinando il Cattolico (1416-1516), IX CSCA (Napoli 1973), II, Napoli, 1982, pp. 461-479.
} 
Già nel gennaio del 1327 il Boixadors si dichiarava soddisfatto dell'espulsione quasi completa dei pullini perciò, secondo la sua opinione, nei primi mesi dell'anno la città sarebbe stata pronta per accogliere le genti iberiche $^{136}$, ma i tempi si rivelarono ben più lunghi per la resistenza degli abitanti a lasciare Bonaria e per i prevedibili contrasti che sorsero nel momento in cui si dovette procedere alle assegnazioni ${ }^{137}$. Varie testimonianze attestano che le difficoltà insorte furono superate solo tra la fine del 1330 e gli inizi del 1331, quando il trasferimento registrò un forte impulso e contemporaneamente la villa di Bonaria appare ormai spopolata ${ }^{138}$.

Agli effettivi problemi legati alle resistenze degli abitanti di Bonaria e agli intoppi che un progetto così complesso comportava, si aggiunsero $\mathrm{i}$ tentativi da parte della comunità di sfruttare al massimo la situazione di disagio per strappare al sovrano l'approvazione di nuovi privilegi. Le lamentele sul grave stato in cui versava la città si unirono alla richiesta di franchigie che, a detta del consiglio municipale, avrebbero dovuto sostenere il processo di trasferimento a Castel di Cagliari ${ }^{139}$, ma in realtà secondo Pere de Llibià, amministratore generale del regno di Sardegna, si trattava di istanze pretestuose, capaci di provocare soltanto un ulteriore depauperamento delle finanze ${ }^{140}$. Il sovrano dovette barcamenarsi tra queste voci discordanti, ma ci sembra di poter dire che accolse in buona misura le richieste della città, largheggiando nelle concessioni e rinnovando l'obbligo del rigoroso rispetto dei privilegi ${ }^{141}$, perché il problema più importante era quello di popolare Castel di Cagliari e ciò sarebbe stato possibile solo con il passaggio di proprietà degli immobili agli abitanti iberici. Nell'aprile del 1328 il sovrano approvò le stime stabilite dalla commissione incaricata del censimento degli edifici, ma ancora nella primavera del 1330 intimava di

\footnotetext{
${ }^{136}$ R. Conde Y Delgado de Molina, Castell de Càller, cit., p. 219.

${ }^{137} \mathrm{La}$ copia trecentesca è stata edita da R. CONDE Y DELGado DE Molina, Castell de Càller, cit. Lo studioso ha sottolineato come, nonostante la commissione che si occupò del censimento fosse mista, i Pisani non avrebbero potuto comunque opporsi a una stima inferiore al reale delle loro case e ricorda a proposito le parole del Boixadors, secondo cui, per favorire una rapida conclusione del trasferimento, si cedevano agli Aragonesi immobili di 400 lire per sole 100 (ibidem, p. 25).

${ }^{138}$ R. CONDE Y Delgado DE Molina, Castell de Câller, cit., pp. 20-ss.

${ }^{139} \mathrm{ACA}, \mathrm{C}, \mathrm{CR}$ di Alfonso III, caja 31, c. 3673 e caja 3, c. 320.

${ }^{140} \mathrm{ACA}, \mathrm{C}, \mathrm{CR}$ di Alfonso III, caja 2, cc. 206 e 250. $211 \mathrm{r}$.

${ }^{141}$ ACA, C, reg. 508, f. $207 v$; reg. 509, ff. 5v-8r; reg. 512, ff. 252-253; reg. 516, ff. 206r-
} 
provvedere con urgenza all'assegnazione delle case rimaste sgombre ${ }^{142}$. Nel corso delle attribuzioni si verificarono varie frodi anche da parte di coloro che avevano stilato il censimento e si erano accaparrati numerosi edifici; nel luglio del 1331 il sovrano richiamò tutti al rispetto degli ordini ricevuti, ribadendo il diritto di possesso di un solo immobile nel castrum per ogni abitante ${ }^{143}$, ma nel 1335 sussistevano ancora gli strascichi di azioni illecite $^{144}$. Talvolta più persone si disputavano l'assegnazione della medesima proprietà e la corte dovette intervenire per dirimere i contrasti; le illegalità inoltre vennero perpetrate anche a danno di alcuni ordini religiosi, come i Vittorini e le Clarisse, che subirono la confisca di beni ${ }^{145}$. Da tutto ciò risulta facile capire come il popolamento provocò una serie interminabile di vertenze giudiziarie e di imbrogli.

Seppure la regola fondamentale nell'attribuzione degli immobili consistesse nella proibizione per i non Iberici di dimorare a Castel di Cagliari, numerose furono le deroghe concesse per lo più a favore di mercanti italiani; costoro diventavano beneficiari a pieno titolo di un immobile, parificando la loro condizione a quella dei cittadini catalani,

\footnotetext{
${ }^{142}$ ACC, Sez. antica, Pergamene, n. 49, regestata da S. LIPPI, L'Archivio Comunale, cit. p. 130. Nel 1331 Alfonso ordinava che venissero rispettate le concessioni di immobili di Castel di Cagliari a favore di coloro che avevano abbandonato Bonaria, ACA, C, reg. 512, ff. 204v205r (R. CONDE y Delgado DE Molina, Castell de Càller, cit., p. 22, n. 34). Ancora il 17 settembre 1333 rinnovava l'ordine relativo al pagamento delle stime delle case: ACA, C, reg. 516, ff. 172v-173r; ACA, C, reg. 1008, f. 86r-v e f. 127r. Sulle case ancora libere ACA, C reg. $510, \mathrm{ff} .155 \mathrm{r}-162 \mathrm{r}$. In realtà la soluzione del prezzo degli immobili non fu un'operazione facile, anche su questo tema infatti, la corte assunse atteggiamenti diversi, il progetto iniziale prevedeva il riscatto degli edifici da parte dei nuovi proprietari, ma alla fine la Corona dovette assumersi l'onere del pagamento. Su alcuni casi si veda: ACA, C, reg. 1007, ff. 162v-163r; reg. 1008 , f. $43 \mathrm{v}$, n. 1 , f. $91 \mathrm{r}-\mathrm{v}$; reg. 1009 , f. 320 , n. 1

${ }^{143} \mathrm{ACA}, \mathrm{C}$, reg. 510, ff. 155r-162r. Nonostante le lacune nel testo, sono chiarissime le accuse lanciate da Alfonso: «al senyor rey és dat a entendre ço que alguns del dits estimadors o partidors són retenguts molts dels dits alberchs [...] entes e en altres maneres fraudolosament». (ibidem, f. 158v). Sul diritto di possedere un solo immobile a Castel di Cagliari: ACC, Sez antica, Pergamene, nn. 94, 101 e 112, regestate da S. LIPPI, L'Archivio Comunale, cit., pp. 140 e 142 .

${ }^{144} \mathrm{ACA}, \mathrm{C}$, reg. 518 , ff. $166 \mathrm{v}-169 \mathrm{v}$ e f. $219 \mathrm{r}, \mathrm{n} .1$.

${ }^{145} \mathrm{Su}$ alcuni casi controversi: ACA, C, reg. 508, f. 152r-v; reg. 511, ff. 35v-36r; reg. 514, f. $145 \mathrm{r}-\mathrm{v}$, ff. $145 \mathrm{v}-146 \mathrm{r}$, ff. $157 \mathrm{r}-158 \mathrm{v}$, f. 216 , n. 2 ; reg. 515 , f. $31 \mathrm{r}-\mathrm{v}$, f. $92 \mathrm{v}-93 \mathrm{r}$; ff. $110 \mathrm{v}-$ $111 \mathrm{r}$, ff. $120 \mathrm{v}-121 \mathrm{r}$; reg. 518, f. $138 \mathrm{r}-\mathrm{v}$, n. 2 , f. $148 \mathrm{r}$; reg. 1006, f. 86r, n. 1; reg. 1033, f $32 \mathrm{r}-\mathrm{v}$. Sulla perdita dei beni da parte del monastero di San Saturno cfr. A. Boscolo, Documenti sull'economia e sulla società in Sardegna all'epoca di Alfonso il Benigno, Padova, 1973, p. 7 , nn. 24 e 26; sul caso delle Clarisse cfr. M.G. MELONI, Note sulla presenza delle Clarisse in Sardegna nel Medioevo, in "Bollettino Bibliografico Sardo", 18 (1994), pp. 43-52.
} 
aragonesi, maiorchini, etc. ${ }^{146}$. Alfonso assicuró una buona sistemazione a personaggi della politica, dell'amministrazione regia, dell'economia, della Chiesa $^{147}$, ma anche a semplici persone, il cui umile lavoro risultava comunque indispensabile, come nel caso del fornaio Gadutxo Cors ${ }^{148}$. Avevano beneficiato della sua magnanimità Pietro, vescovo di Santa Giusta, del giudicato d'Arborea, che ottenne il diritto vitalizio di possesso di un immobile a Castel di Cagliari, in realtà inteso quale saldo di un debito contratto dalla corte ${ }^{149}$, e anche gli esponenti religiosi di origine pisana

\footnotetext{
${ }^{146} \mathrm{Gli}$ esempi sono numerosissimi, basta ricordare: ACA, C, reg. 508, f. $151 \mathrm{v}$; reg. 509 , f. $61 \mathrm{v}$; reg. 512 , f. 267 r-v, ff. $290 v-291$ v, ff. $291 v-292$ r, f. 292 r, f. $297 v$, n. 1 ; reg. 514 , ff 165r-166r, ff. 166r-167r, ff. 175v-176r, f. 176r-v; reg. 518, ff. 200v-201r, f. 223v, n. 2. Cfr. F.C. Casula, La cancelleria di Alfonso III il Benigno re d'Aragona (1327-1336), Padova, 1967 , p. 77 , n. 76 . Un provvedimento esattamente opposto venne assunto il 19 dicembre 1334 , con cui si annullavano gli acquisti di immobili fatti da parte dei Pisani, Fiorentini e ad altri sudditi di nazioni straniere, cfr. M. PINNA, Indice, cit., p. 23, n. 102. Un comportamento altalenante da parte di Alfonso determinò l'assunzione di provvedimenti contrastanti a favore di personaggi pisani, casi emblematici quelli di Lotto Serragli e Maxerono Bonaquisto, su cui i dati sono numerosi, a proposito si vedano: ACA, C, reg. 515 , f. $31 \mathrm{r}-\mathrm{v}$, f. $107 \mathrm{r}$, ff. $116 \mathrm{r}-118 \mathrm{r}$, f. $126 \mathrm{v}$; reg. 514 , ff. $166 \mathrm{v}-169 \mathrm{v}$; reg. 516 , ff. $200 \mathrm{v}-201 \mathrm{v}$, ff. $258 \mathrm{r}-263$ r e f. $268 \mathrm{v}$; reg. 1009 , f. 250v. Anche durante il regno di Pietro IV non mancarono le concessioni del diritto di residenza a non Iberici. Interessante il caso del magister Marino fisicus, di origine sarda, a cui venne concesso di risiedere a Castel di Cagliari per svolgere la sua professione a sostegno degli indigenti: ACA, C, reg. 1007, ff. 202v-203r (1337) e quello del notaio Leonardo Romano che poté acquistare un immobile, nonostante i divieti esistenti (ibidem, ff. 201v-202r, anno 1337). Nel 1338 Ramon de Ribelles intercesse presso il sovrano a favore del medico Martino Lagi che lo aveva in cura da molto tempo, assicurandogli il diritto di residenza a Castel di Cagliari: L. D'ARIEnzo, Carte reali diplomatiche di Pietro IV il Cerimonioso, re d'Aragona, riguardanto l'Italia, Padova, p. 21, n. 40.

${ }^{147}$ Ricevettero immobili a Castel di Cagliari: Pere Plana (ACA, C, reg. 512, f. 267v e f. 268r, n. 1), il procuratore fiscale Pere de Castelló (ibidem, reg. 514, ff. 158v-159r), il chirurgo Burdo de Molina, che ottenne una curia operatoria (A. BosColo, Documenti sull'economia, cit., p. 20, nn. 66-67). Una casa fu assegnata rispettivamente a un certo Jaume Metge, al medico Grazia Orlandi (ACA, C, reg. 515, f. 104v, f. 105r, f. 106v), ai fedeli Arnau de Ladrera e Berenguer Rajadell (ACA, C, reg. 511, f. 19r; reg. 514, f. 261r e reg. 515, f. 110rv), al doganiere Guerau Voltor (ACA, C, reg. 516, f. 274r), al notaio barcellonese Jaume d'Oliver (ACA, C, reg. 516, f. 125v), al figlio maggiore di Bernat de Segura, rettore e cellario di Castel di Cagliari (ACA, C, reg. 517, f. 49v), all'apothecarius maiorchino Pere Negrell (ACA, C, reg. 517, f. 62r-v), a Felip de Boï (ACA, C, reg. 518, ff. 202v-204r), a Bernat Descoll (ACA, C, reg. 518, f. 220, n. 1), all'apothecarius Guillem Camaller (ACA, C, reg. 517 , ff. $59 \mathrm{v}-60 \mathrm{r})$ etc.

${ }^{148} \mathrm{ACA}, \mathrm{C}$, reg. 517 , f. $22 \mathrm{v}$. Il fornaio, non potendo risiedere a Castel di Cagliari, avrebbe dovuto attendere ogni giorno l'apertura delle porte della città per recarsi nella sua bottega e ciò avrebbe provocato un ritardo nel processo di panificazione.
}

${ }^{149} \mathrm{ACA}, \mathrm{C}$, reg. 512 , f. $235 \mathrm{r}-\mathrm{v}$, f. $235 \mathrm{v}$, nn. $1-2$. 
proprietari di immobili, mentre si attendeva l'occasione propizia per sottrarne loro il possesso con un'accusa di tradimento ${ }^{150}$.

Sin dalla conquista della città il sovrano aveva provveduto ad affidare gli immobili di maggior pregio ai suoi servitori più fedeli ${ }^{151}$ e per le pressioni di personaggi autorevoli o forse per la densità abitativa raggiunta in città inferiore alle aspettative, non esitò a modificare alcuni dei cardini che avrebbero dovuto guidare il processo di assegnazione degli edifici, concedendo, per esempio, il diritto di proprietà di due immobili contigui ad una stessa persona ${ }^{152}$.

In conclusione, Castel di Cagliari fu preferita a Bonaria quale capitale del regno sardo: al di là degli ambiziosi progetti iniziali, la corte ripiegò sull'efficienza del centro pisano, concentrò le proprie risorse nel mantenimento della struttura difensiva e nello sviluppo dell'appendice della Lapola, decretando la fine della prima villa catalana. Nonostante i problemi che sarebbero sorti di lì a poco, la scelta compiuta si rivelò determinante perché Castel di Cagliari costituì una risorsa fondamentale e divenne un punto chiave della resistenza catalana impegnata nella lunga guerra contro il regno di Arborea.

\footnotetext{
${ }^{150}$ Un caso emblematico è quello del canonico Saladino Pisanello che avrebbe conservato una casa di sua proprietà a Castel di Cagliari solo se fosse stato giudicato innocente nel processo a cui venne sottoposto per accusa di tradimento: ACA, C, reg. 516, f. 270r, n. 1 (1334 aprile 4); reg. 517 , f. 59v (1334 luglio 22) e ff. 59v-60r (1334 luglio 24).

${ }^{151}$ Anche in questo caso la documentazione è ricca di esempi: sul caso del Boixadors, vedi supra, nota 100; ottenne un competens hospicium Brenta, viceammiraglio e vicario di Castel di Cagliari (ACA, C, reg. 512, f. 252r, n. 1 e f. 267v), mentre ricevettero alcuni fra i migliori hospicia Guillem Olomar (ACA, C, reg. 403, f. 171r-v; reg. 512, f. 292r, n. 1), Gallard de Mallol (ACA, C, reg. 403, f. 179v), Arnau de Cassà (ACA, C, reg. 403, f. 199r-v).

${ }^{152} \mathrm{Nel}$ luglio del 1331 Alfonso confermava il diritto del possesso di un solo immobile a Castel di Cagliari, ma allo stesso tempo concedeva la possibilità di mantenere due immobili attigui: ACA, C, reg. 512, ff. 200v-201r. Furono beneficiari di due case attigue personaggi come Ramon Savall, che adibì uno dei due locali per la sede della sua società commerciale (ACA, C, reg. 512, f. 275v), Arnau de Cassà (ACA, C, reg. 513, f. 45r-v), Guillem Arnau (ACA, C, reg. 513, f. 103r-v), Pere de Mitjavila (ACA, C, reg. 514, ff. 202v-203r); si veda anche ACA, C, reg. 513, f. 43r-v.
} 
APPENDICE I

Concessioni di terreni in/presso Bonaria

\begin{tabular}{||l|l|l|l||}
\hline \multicolumn{1}{|c|}{ DATA } & NOME & PROFESSIONE & PROVENIENZA \\
\hline 1324 aprile $25^{1}$ & $\begin{array}{l}\text { Guillem Gavarra } \\
\text { Francesc Alfons } \\
\text { Remolar }\end{array}$ & & \\
\hline 1324 luglio $12^{2}$ & Giorgio Zori & armentarius & \\
\hline 1324 settembre $20^{3}$ & Bernat Arbocet & & \\
\hline 1325 maggio $4^{4}$ & Guillem Jordà & $\begin{array}{l}\text { rettore della } \\
\text { chiesa di Bonaria }\end{array}$ & \\
\hline 1325 luglio $11^{5}$ & Ramon Savall & mercante & Barcellona \\
\hline 1325, settembre $17^{7}$ & $\begin{array}{l}\text { Teresa Gombau } \\
\text { de Entença }\end{array}$ & $\begin{array}{l}\text { moglie di Beren- } \\
\text { guer Carròç }\end{array}$ & \\
\hline 1325, novembre $22^{8}$ & Garcia de Loriç & pesatore regio & \\
\hline
\end{tabular}

'ACA, C, reg. 392, f. 197v. Concessione di un terreno prope Bonayre.

${ }^{2} \mathrm{ACA}, \mathrm{C}$, reg. 398, ff. 19v-20r. Si tratta in realtà della concessione di diversi terreni ad uso agricolo compresi in un'area molto vasta, ma non mancavano lotti prossimi alla collina di Bonaria, si concedevano infatti "...duo trocia terre sita et posita in curatoria de Campitano in villa que dicitur Quartu Toco et Quartu Donici, quequidem duo trocia terre scilicet primum confrontatur ex una parte in via publica et ex alia parte in terra Sancti Saturni et ex alia parte cum via que vocatur via de sale et ex alia parte cum via que itur ad // Castrum Callari. Aliud trocium affrontatur ex una parte cum via que itur ad dictum Castrum et ex alia parte cum terra heredum Alberti de Ferro et ex alia parte cum via publica et partim cum terra ecclesie sancti Leonardi et ex alia parte cum vinea Gomite Nasu".

${ }^{3} \mathrm{ACA}, \mathrm{C}$, reg. 390 , f. 174 r.

${ }^{4} \mathrm{ACA}, \mathrm{C}$, reg. 342 , ff. $363 \mathrm{v}-365 \mathrm{r}$. Si concedono al rettore de Bonaria tre pezzi di terra: uno per costruire una residenza, il secondo come cimitero, il terzo come vigna. Si trata della conferma di un precedente documento datato 13 aprile del 1325.

${ }^{5}$ ACA, C, reg. 399, ff. 58v-59r.

${ }^{6} \mathrm{Da}$ varie fonti successive risulta essere stato nominato a capo dell'ufficio dell'amministrazione generale del regno di Sardegna.

${ }^{7} \mathrm{ACA}, \mathrm{C}$, reg. 399 , f. $117 \mathrm{v}$. Si concedono "quasdam domos seu hospicium... in villa Castri de Bonayre". 
NUOVI ELEMENTI DI STORIA URBANA NEL REGNO DI SARDEGNA

\begin{tabular}{||l|l|l|l||}
\hline 1326 gennaio $30^{9}$ & $\begin{array}{l}\text { Torronsa Mayas- } \\
\text { sendis }\end{array}$ & Gerona \\
\hline 1326 marzo $19^{10}$ & $\begin{array}{l}\text { Ramon, Bernat, } \\
\text { Jaume Roig }\end{array}$ & & \\
\hline 1326 marzo $29^{11}$ & Pere de Canelles & & $\begin{array}{l}\text { parrocchia di } \\
\text { Sant'Andrea de } \\
\text { Palomar, diocesi } \\
\text { di Barcellona }\end{array}$ \\
\hline 1326 aprile $27^{12}$ & Bonanat Sapera & notaio & Berenguer de \\
\hline 1326 aprile $29^{13}$ & Rivardell & & Barcellona \\
\hline 1326 maggio $10^{14}$ & Jaume Daniort & carpentiere & Maiorca \\
\hline 1326 maggio $15^{15}$ & Joan [****] & & Barcellona \\
\hline 1326 maggio $15^{16}$ & Guillem Barceló & vetraio & Maiorca \\
\hline 1326 maggio $17^{17}$ & Guillem & magister operae & Barcellona \\
\hline 1326 maggio $23^{18}$ & Antoni Vaquer & cordaio & \\
\hline
\end{tabular}

${ }^{8}$ ACA, C, reg. 400 , ff. $141 v-142$ r. Si concede "quoddam cellarium curie Castri nostri de Bonayre".

${ }^{9} \mathrm{ACA}, \mathrm{C}$, reg. 376, f. 89r-v. Si concede un patuum terre da edificare nella villa di Bonaria.

${ }^{10} \mathrm{ACA}, \mathrm{C}$, reg. 400 , f. $198 \mathrm{r}$. Si concedono "patua in loco castri de Bonayre iuxta portam Beate Marie de Portu".

"ACA, C, reg. 400, f. 219v. Patua in Bonaria.

${ }^{12} \mathrm{ACA}, \mathrm{C}$, reg. 400 , ff. 203v-204r. Si tratta di un terreno appartenuto al pisano Segueri Porcellino, a lui sottratto da parte di Francesc Carròs e successivamente assegnato dall'infante Alfonso a Bonanat Sapera.

${ }^{13} \mathrm{ACA}, \mathrm{C}$, reg. 400 , f. 219 r. Patuum in Bonaria.

${ }^{14} \mathrm{ACA}, \mathrm{C}$, reg. 400 , f. 230v. Patuum in Bonaria.

${ }^{15} \mathrm{ACA}, \mathrm{C}$, reg. 401 , f. 1v. Patuum in Bonaria.

${ }^{16} \mathrm{ACA}, \mathrm{C}$, reg. 401, f. 6r. Alfonso concede a Guillem Barceló varie proprietà, tra cui "aliquod decens patium in litore maris quo est intus Castrum Callari et Castrum de Bonayre in quo possit construere hospicium ut vitrum suum tenere et vendere valeat in eodem".

${ }^{17} \mathrm{ACA}, \mathrm{C}$, reg. 401 , f. $12 \mathrm{r}-\mathrm{v}$. Si tratta della concessione di un terreno e di una grotta.

${ }^{18} \mathrm{ACA}, \mathrm{C}$, reg. 401 , f. $14 \mathrm{r}$. 


\begin{tabular}{||l|l|l|l||}
\hline 1326 maggio $25^{19}$ & $\begin{array}{l}\text { Guillem Bonen- } \\
\text { contre }\end{array}$ & hostiarius & \\
\hline 1326 giugno $5^{20}$ & Bernat de Segura & pittore & Barcellona \\
\hline 1326 giugno $5^{21}$ & Pere Sasala & & Barcellona \\
\hline 1326 giugno $8^{22}$ & $\begin{array}{l}\text { Guillem Cor- } \\
\text { nalboix }\end{array}$ & magister operae & Illa de Vall \\
\hline 1326 luglio $22^{23}$ & Bernat Mestre & fabbro & Barcellona \\
\hline 1326 agosto $1^{24}$ & Jaume Descoll & & \\
\hline 1326 agosto $6^{25}$ & Pere d'Ars & & Barcellona \\
\hline
\end{tabular}

\section{APPENDICE II}

Concessioni di case a Castel di Cagliari

\begin{tabular}{||l|l|l|l||}
\hline DATA & NOME & PROFESSIONE & PROVENIENZA \\
\hline 1326 febbraio $22^{1}$ & Francesc Desplà & medico & \\
\hline 1326 febbraio $26^{2}$ & Bernat de Palau & hostiarius & \\
\hline 1326 marzo $5^{3}$ & Pere Oliver & & \\
\hline
\end{tabular}

\footnotetext{
${ }^{19}$ ACA, C, reg. 400 , f. $244 \mathrm{r}$.

${ }^{20} \mathrm{ACA}, \mathrm{C}$, reg. 401 , f. $30 \mathrm{r}-\mathrm{v}$. Si concede un lotto di terreno per costruire una casa e una

${ }^{21} \mathrm{ACA}, \mathrm{C}$, reg. 401, f. 36v. Concessione di un terreno per costruire una casa in Bonaria.

${ }^{22} \mathrm{ACA}, \mathrm{C}$, reg. 401 , f. $30 \mathrm{v}$.

${ }^{23} \mathrm{ACA}, \mathrm{C}$, reg. 401 , f. 81 v. Patua in Bonaria.

${ }^{24} \mathrm{ACA}, \mathrm{C}$, reg. 401 , f. $111 \mathrm{r}$. Concessione di un "patuum terre in casrtro de Bonayre in quo hedificare valeat unum condecens hospicium".

${ }^{25} \mathrm{ACA}, \mathrm{C}$, reg. 401 , f. $36 \mathrm{v}$.

'ACA, C, reg. 400, ff. 185r-186r.

${ }^{2}$ ACA, C, reg. 400 , f. 190 r-v.

${ }^{3}$ ACA, C, reg. 400, f. 191r. (cfr. ibidem, ff. 194r-195r).
} bottega. 


\begin{tabular}{||l|l|l|l||}
\hline 1326 marzo $10^{4}$ & Pere Agustí & $\begin{array}{l}\text { luogotenente del } \\
\text { maestro razionale }\end{array}$ & \\
\hline 1326 marzo $13^{5}$ & Arnau Ferran & cuyraterius & Barcellona \\
\hline 1326 marzo $14^{6}$ & $\begin{array}{l}\text { Bernat de Boixa- } \\
\text { dors }\end{array}$ & riformatore regio & \\
\hline 1326 marzo $13^{7}$ & Ramon de Besalú & hostiarius & \\
\hline 1326 marzo $13^{8}$ & Pere Plana & hostiarius & \\
\hline 1327 gennaio $30^{9}$ & Bernat de Boixa- & $\begin{array}{l}\text { governatore } \\
\text { regio }{ }^{10}\end{array}$ & \\
\hline 1327 gennaio $30^{11}$ & Guillem Desllor & $\begin{array}{l}\text { ax-camarlengo di } \\
\text { Sassari }\end{array}$ & \\
\hline 1327 marzo $2^{12}$ & Guillem Sima & amministratore & \\
generale & & \\
\hline 1327 giugno $6^{13}$ & Pere de Llibià & &
\end{tabular}

${ }^{4}$ ACA, C, reg. 400, f. $194 \mathrm{v}$, n. 1 .

${ }^{5} \mathrm{ACA}, \mathrm{C}$, reg. 400, f. 196r-v. Concessione di un hospicium e un orto a Castel di Cagliari.

${ }^{6} \mathrm{ACA}, \mathrm{C}$, reg. 400 , ff. $196 \mathrm{v}-197 \mathrm{r}$.

${ }^{7} \mathrm{ACA}, \mathrm{C}$, reg. 400 , f. 197v. Si trattava di un hospicium del valore di 4.000 soldi alfonsini.

${ }^{8} \mathrm{ACA}, \mathrm{C}$, reg. 400 , f. $197 \mathrm{r}$-v. La concessione non trovò attuazione e il 26 luglio del 1326 venne commutata con l'offerta di un ufficio (ACA, C, reg. 401, f. 88r-v).

${ }^{9} \mathrm{ACA}, \mathrm{C}$, reg. 403, ff. $1 \mathrm{v}-2 \mathrm{v}$. Concessione di un hospicium appartenuto all'Opera di Santa Maria de Pontis di Pisa. Conferma della stessa concessione ibidem, ff. 79v-80r. A favore del Boixadors esiste un'ulteriore rinnovo del diritto di proprietà di vari immobili a Castel di Cagliari ibidem, f. 80r.

${ }^{10}$ Nell'agosto del 1326 Bernat de Boixadors, dopo aver rivestito l'incarico di riformatore regio, venne nominato governatore del regno di Sardegna: ACA, C, reg. 402, f. 144r.

"ACA, C, reg. 402, ff. 241v-242r.

${ }^{12} \mathrm{ACA}, \mathrm{C}$, reg. 403, f. 52r. Si concede un hospicium a Castel di Cagliari e un patuum nella Lapola (vedi Appendice III).

${ }^{13} \mathrm{ACA}, \mathrm{C}$, reg. 403 , ff. $73 \mathrm{v}-75 \mathrm{v}$. Pere de Llibià ricevette ben quattro hospicia nella via dei marinai apartenuti al pisano Neri Moxarif.

${ }^{14}$ Questo personaggio ottene la carica di vicario all'inizio dell'impresa della conquista (ACA, C, reg. 396, f. 17r., 29 settembre 1323), nel giugno del 1325 risulta però essere a capo dell'amministrazione del regno di Sardegna con Arnau de Cassà. 


\begin{tabular}{||l|l|l|l||}
\hline 1327 giugno $7^{15}$ & $\begin{array}{l}\text { Pere Guulllem de } \\
\text { Folquers }\end{array}$ & notaio & \\
\hline 1327 luglio $10^{16}$ & Grazia Orlandi & medico & \\
\hline 1327 luglio $21^{17}$ & Arnau de Cassà & $\begin{array}{l}\text { amministratore } \\
\text { generale }{ }^{18}\end{array}$ & \\
\hline 1327 agosto $1^{19}$ & Bonanat Sapera & notaio & \\
\hline 1327 agosto $5^{20}$ & Guillem Olomar & cancelliere regio & \\
\hline 1327 agosto $7^{21}$ & Bernat Despont & & \\
\hline 1327 agosto $21^{22}$ & Gallart de Mallol & & \\
\hline
\end{tabular}

APPENDICE III

Concessioni di terreni nella Lapola

\begin{tabular}{||c|l|l|l||}
\hline DATA & \multicolumn{1}{|c|}{ NOME } & PROFESSIONE & PROVENIENZA \\
\hline 1327 gennaio $27^{1}$ & Guillem Bonfill & & \\
\hline 1327 febbraio $27^{2}$ & Guillem Sapera & & \\
\hline 1327 febbraio $27^{3}$ & Llop de Conçut & scrivano & \\
\hline
\end{tabular}

${ }^{15} \mathrm{ACA}, \mathrm{C}$, reg. 403 , f. 97 r. Pere Guillem de Folquers acquistò un hospicium appartendo al pullino Vanni de la Cita, del valore di 85 lire genovine.

${ }^{16} \mathrm{ACA}, \mathrm{C}$, reg. 403, ff. $104 \mathrm{v}-105 \mathrm{v}$; ff. $105 \mathrm{v}-106 \mathrm{r}$. Si tratta in realtà della conferma delle proprietà già appartenute a Gracia Orlandi e al padre Tomaso.

${ }^{17} \mathrm{ACA}, \mathrm{C}$, reg. 403, f. 199r-v. Si concede un hospicium a Castel di Cagliari, uno stagium in Stampace e un patuum in Lapola (vedi Appendice III).

${ }^{18} \mathrm{M}$. TANGHERONI, Alcuni aspetti, cit., p. 125.

${ }^{19} \mathrm{ACA}, \mathrm{C}$, reg. 403, ff. 158v-159r. Bonanat Sapera ottenne varie concessioni, tra cui un immobile a Castel di Cagliari e un patuum in Lapola (vedi Appendice III).

${ }^{20} \mathrm{ACA}, \mathrm{C}$, reg. 403, f. 171 r-v. Guillem Olomar aveva dovuto restituire un immobile appartenuto a Maxerono Bonaquisto, la corte gli concesse pertanto un nueovo hospicium.

${ }^{21} \mathrm{ACA}, \mathrm{C}$, reg. 403, f. 169r-v. Si concede un hospicium a Castel di Cagliari, uno in Stampce e un patuum in Lapola (vedi Appendice III).

${ }^{22}$ ACA, C, reg. 403 , f. $179 v$, n. 2.

'ACA, C, reg. 402 , f. $244 \mathrm{v}$, n. 1 .

${ }^{2} \mathrm{ACA}, \mathrm{C}$, reg. 403 , f. $46 \mathrm{v}$.

${ }^{3} \mathrm{ACA}, \mathrm{C}$, reg. 403 , ff. $46 \mathrm{v}-47 \mathrm{r}$. 
NUOVI ELEMENTI DI STORIA URBANA NEL REGNO DI SARDEGNA

\begin{tabular}{|c|c|c|c|}
\hline 1327 febbraio $27^{4}$ & $\begin{array}{l}\text { Pere, Jaume e } \\
\text { Francesc Gualbes }\end{array}$ & mercanti & \\
\hline 1327 febbraio $27^{5}$ & $\begin{array}{l}\text { Bernat Ballester } \\
\text { Arnau Ballester }\end{array}$ & $\begin{array}{l}\text { magister maior } \\
\text { monte Ville } \\
\text { Ecclesie } \\
\text { scrivano }\end{array}$ & \\
\hline 1327 febbraio $27^{6}$ & $\begin{array}{l}\text { Ramon e Bernat } \\
\text { Savall }\end{array}$ & mercanti & Barcellona \\
\hline 1327 febbraio $27^{7}$ & Bernat de Vilardell & & Barcellona \\
\hline 1327 febbraio $27^{8}$ & $\begin{array}{l}\text { Arnau Dusay, } \\
\text { Berenguer Guerau }\end{array}$ & mercanti & Barcellona \\
\hline 1327 febbraio $28^{9}$ & $\begin{array}{l}\text { Guillem Olomar, } \\
\text { Guillem d'Abadia } \\
\text { Bonanat Sapera }\end{array}$ & $\begin{array}{l}\text { cancelliere regio } \\
\text { baiulo }^{10} \\
\text { notaio }\end{array}$ & \\
\hline 1327 febbraio $28^{\prime \prime}$ & Arnau Mascaró & scudiero & \\
\hline 1327 febbraio $28^{12}$ & $\begin{array}{l}\text { Bernat } \\
\text { Bernat Iserni } \\
\text { Deusvol de } \\
\text { Canois }{ }^{13} \\
\text { Arnau Destorrents }\end{array}$ & $\begin{array}{l}\text { baiulo e camer- } \\
\text { lengo di Sassari } \\
\text { mercante } \\
\text { mercante } \\
\text { mercante }\end{array}$ & $\begin{array}{l}\text { Barcellona } \\
\text { Barcellona } \\
\text { Barcellona }\end{array}$ \\
\hline
\end{tabular}

${ }^{4} \mathrm{ACA}, \mathrm{C}$, reg. 403, f. 47r.

${ }^{5} \mathrm{ACA}, \mathrm{C}$, reg. 403 , f. $47 \mathrm{r}$ n. 2.

${ }^{6} \mathrm{ACA}, \mathrm{C}$, reg. 403 , f. $47 \mathrm{v}$.

${ }^{7} \mathrm{ACA}, \mathrm{C}$, reg. 403 , f. $47 \mathrm{v}$, n. 2.

${ }^{8} \mathrm{ACA}, \mathrm{C}$, reg. 403 , f. $47 \mathrm{v}$, n. 3.

${ }^{9} \mathrm{ACA}, \mathrm{C}$, reg. 403. ff. $45 \mathrm{v}-46 \mathrm{r}$. Una precedente concessione sempre risalente al febbraio del 1327 si trova ibidem, reg. 403 , f. 12 r.

${ }^{10}$ In realtà Guillem d'Abbadia rivestiva l'incarico di baiulo, portolano e doganiere.

"ACA, C, reg. 403, f. 46r, n. 2.

${ }^{12} \mathrm{ACA}, \mathrm{C}$, reg. 403, f. 48r.

${ }^{13}$ Questo personaggio aveva già ottenuto nel marzo del 1326 l'attribuzione di un terreno nell'area della Lapola (ACA, C, reg. 400, ff. 191v-192r.). 


\begin{tabular}{|c|c|c|c|}
\hline 1327 marzo $2^{14}$ & Guillem Sima & $\begin{array}{l}\text { ex-camerlengo di } \\
\text { Sassari }\end{array}$ & \\
\hline 1327 marzo $2^{15}$ & Joan de la Geltrú & apothecarius & \\
\hline 1327 marzo $11^{16}$ & $\begin{array}{l}\text { Berenguer Salva- } \\
\text { dor } \\
\text { Francesc Mateu }\end{array}$ & scrivani & \\
\hline 1327 luglio $21^{17}$ & Arnau de Cassà & $\begin{array}{l}\text { amministratore } \\
\text { generale }\end{array}$ & \\
\hline 1327 agosto $1^{18}$ & Bonanat Sapera & notaio & \\
\hline 1327 agosto $1^{19}$ & Bernat Despont & & \\
\hline 1327 agosto $1^{20}$ & $\begin{array}{l}\text { Felip de Boyl } \\
\text { Guillem Olomar } \\
\text { Ramon Savall } \\
\text { Bonanat Sapera }\end{array}$ & $\begin{array}{l}\text { maestro razion. } \\
\text { cancelliere reg. } \\
\text { amministratore } \\
\text { generale } \\
\text { notaio }\end{array}$ & Barcellona \\
\hline
\end{tabular}

\section{RÉSUMÉ}

À l'occasion du siège mis devant la ville de Castel di Cagliari durant le conflit qui les opposait aux Pisans, les Catalans s'établirent dans un site jusqu'alors inhabité, non loin de la place forte pisane, à laquelle ils donnèrent le nom de Bonaria. Le campement militaire se transforma cependant bien vite en une ville fortifiée et peuplée, dont le développement soutenu par la cour avec des moyens exceptionnels, visait à provoquer la décadence économique de Castel di Cagliari, et, par conséquent, l'éloignement définitif des Pisans.

Une riche documentation inédite permet de reconstruire le processus de développement de la ville de Bonaria jusqu'à la conquête de Castel di Cagliari et d'établir les raisons

${ }^{14} \mathrm{ACA}, \mathrm{C}$, reg. 403, f. 52r. Da un altro documento risulta che lo stesso personaggio ottenne 2.000 soldi genovesi: ibidem, ff. $51 v-52 r$.

${ }^{15} \mathrm{ACA}, \mathrm{C}$, reg. 316, f. 24r. Joan de la Geltrú ottenne un terreno nella Lapola in cambio della mancata assegnazione di un hospicium a Castel di Cagliari.

${ }^{16} \mathrm{ACA}, \mathrm{C}$, reg. 403, f. $60 \mathrm{r}-\mathrm{v}$.

${ }^{17} \mathrm{ACA}, \mathrm{C}$, reg. 403 , f. $199 \mathrm{r}-\mathrm{v}$.

${ }^{18} \mathrm{ACA}, \mathrm{C}$, reg. 403, ff. 156v-159r.

${ }^{19} \mathrm{ACA}, \mathrm{C}$, reg. 403 , f. $169 \mathrm{r}-\mathrm{v}$.

${ }^{20} \mathrm{ACa}, \mathrm{C}$, reg. 403 , ff. $157 \mathrm{r}-158 \mathrm{r}$. 
pour lesquelles l'infant Alphonse, malgré l'opposition d'une partie des forces sociales, put modifier ses plans initiaux et faire converger à Castel di Cagliari les intérêts économiques catalans. Les recherches effectuées offrent en outre une nouvelle contribution à l'histoire urbaine, par l'analyse détaillée du projet de fondation et de qualification économique de la zone maritime (Lapola) réalisé au moyen d'une catalanisation systématique des divers aspects de la vie sociale.

\section{SUMMARY}

During the war against Pisa for the dominion of Sardinian Kingdom, the Catalans established their first settlement on the island in a site until then uninhabited, originally a military camp called Bonaria. It developed rapidly and very soon had a dense population of inhabitants, emigrants from the Kingdoms of the Crown of Aragon. Alfonso's plan, heir to the Aragonese throne, was to reinforce the anti-Pisan function of Bonaria, in order to provoque an economic crisis and a subsequent withdrawal of the enemies from Castel di Cagliari.

According to sources, it is possible to reconstruct the evolution of the town-planning policy of Bonaire until the conquest of Castel di Cagliari, when Alfonso decided to populate the pisan castrum and accompanied this project with a program to boost the economic activity in the port of Lapola, through a privilege system; indeed within the Catalans Castel di Cagliari carried out a mainly defensive-political and commercial role. The research offers also a new contribution of the Sardinian urban history; in fact, it analyses the project of Lapola's foundation and the systematic catalanization of life standards. 